\title{
Bacterial drift and dispersal drive microbiome diversity within a population of feral hindgut fermenters
}

\author{
Mason Stothart ${ }^{1}$, Ruth Greuel ${ }^{2}$, Stefan Gavriliuc ${ }^{1}$, Astrid Henry ${ }^{1}$, Alastair Wilson ${ }^{3}$, Philip \\ McLoughlin ${ }^{2}$, and Jocelyn Poissant ${ }^{1}$ \\ ${ }^{1}$ University of Calgary \\ ${ }^{2}$ University of Saskatchewan \\ ${ }^{3}$ University of Exeter
}

September 10, 2020

\begin{abstract}
Studies of microbiome variation in the wild often emphasize host physiology and diet as proximate selective pressures acting on host-associated microbiota. In contrast, microbial dispersal is more rarely considered, and when it is, spatially autocorrelated environmental variables are sometimes overlooked. Using amplicon sequencing, we characterized the bacterial microbiome of adult female $(\mathrm{n}=86$ ) Sable Island horses (Nova Scotia, Canada) as part of a detailed, individual-based study of the ecology and evolution of this unmanaged free-living population. Using data on sampling date, horse location, age, parental status, and local exposure to habitat variables, we contrasted the ability of spatiotemporal, physiological, and environmental factors to explain microbiome diversity among Sable Island horses. We extended inferences made from these analyses with both phylogeny-informed and phylogeny-independent null modeling approaches to identify deviations from stochastic expectations. Phylogeny-informed diversity measures were more often correlated with local habitat composition, although null modeling results did not support differential selection acting on the microbiome as the mechanism for these correlative patterns. Conversely, phylogeny-independent diversity measures were best explained by spatial terms, with evidence for spatial- and host socialstructured bacterial dispersal limitation. Parental status was important but correlated with measures of $\beta$-dispersion rather than $\beta$-diversity (mares without foals had lower alpha diversity and more variable microbiomes than mares with foals). Our results suggest that inter-host microbiome variation in this population is driven more strongly by bacterial dispersal limitation and ecological drift than by differential selective pressures, highlighting the need to consider alternative ecological processes in the study of microbiomes.
\end{abstract}

\section{1 | Introduction}

Research on the microbiome ecology of wild animals, where ecological and evolutionary processes free from human intervention shape diversity, is key to understanding the form and causes of observed microbiome variation in nature. Exploration of new systems necessarily begins with characterizing the form and putative causes of microbiome variation observed among hosts, host populations, or host species. Following methods of clinical research, aspects of host physiology (Amato et al., 2014; Stothart, Palme, \& Newman, 2019; Suzuki et al., 2019) and diet (Kartzinel, Hsing, Musili, Brown, \& Pringle, 2019; Teyssier et al., 2020) remain heavily emphasized to the neglect of the fuller breadth of ecological processes which shape community variation (selection, ecological drift, and dispersal; Vellend et al., 2014). Niche-based processes (i.e., selection) are sometimes assumed by default, with stochastic processes such as ecological drift (chance demographic change in a population) more rarely taken into account (Adair \& Douglas, 2017; Zhou \& Ning, 2017). Similarly, microbiota dispersal (e.g. spatial, temporal, or social isolation) - while generally ignored beyond co-housing considerations in clinical research - is a natural process integral to microbial ecology within free-living systems 
(Greyson-Gaito et al., 2020). Yet, studies of wildlife microbiomes also overlook dispersal in favour of putative mechanisms related to host diet and physiology.

While host physiology and diet clearly shape wildlife-microbiome variation, the ability of microbiota to disperse between host intestinal tracts arguably supersede the importance of either in governing microbiome diversity (Miller, Svanbäck, \& Bohannan, 2018). Correlations between microbiome composition and social networks in gregarious hosts illustrate the importance of microbial community connectivity and bacterial dispersal on microbiome diversity (savannah baboons [Papio cynocephalus] , Tung et al., 2015; Sarkar et al., 2020). Bacterial dispersal between hosts can occur through grooming (rhesus macaques [Macaca mulatta ], Balasubramaniam et al., 2018), coprophagy (Brandt's vole [Lasiopodomys brandtii ], Bo et al., 2020), shared environment (humans [Homo sapiens ], Rothschild et al., 2018), or copulation (black legged kittiwakes [Rissa tridactyla ], White et al., 2010). Therefore, we would expect rates of bacterial dispersal to decrease as a function of the time and space separating hosts. An effect of spatial separation has been demonstrated at large spatial scales between (sub)populations of red squirrels (Tamiasciurus hudsonicus ; $7 \mathrm{~km}$; Ren et al., 2017), bighorn sheep ( $150 \mathrm{~km}$; Couch et al., 2020), house mice (Mus musculus ; $1100 \mathrm{~km}$; Linnenbrink et al., 2013), American pika (Ochotona princeps ; $1400 \mathrm{~km}$; Kohl, Varner, Wilkening, \& Dearing, 2018), red

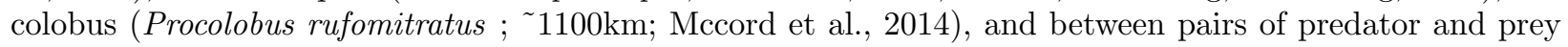
species ( ${ }^{2} 12100 \mathrm{~km}$; Moeller et al., 2017).

The affects of spatial separation on microbial dispersal between social groups of host individuals within populations are more rarely considered. One study of a single focal population of house mice found a greater importance of fine-scale habitat heterogeneity than spatial separation (Goertz et al., 2019). Conversely, spatial structuring of the microbiome has been reported among a contiguous moose population spanning $150 \mathrm{~km}$ (Fountain-Jones et al., 2020). Similar effects of spatial proximity have been observed among semiferal ponies (40 $\mathrm{km}^{2}$; Antwis, Lea, Unwin, \& Shultz, 2018), but were limited to comparisons between three large social groups (bands). Regardless of the spatial scale considered, many studies do not control for local environmental variation, which can be problematic given an expectation of spatial autocorrelation in environmental conditions. Conversely, studies which consider environmental terms often do not consider spatial processes.

Although spatial proximity and social networks can facilitate dispersal between hosts and can thereby drive microbiome similarity, strong dispersal limitation can cause greater than expected divergence between communities and unpredictable $\beta$-diversity patterns. In a meta-population context, dispersal between communities are thought to stabilize populations (Crowley, 1981), so long as dispersal is not so high as to drive spatial synchrony (Yaari, Ben-Zion, Shnerb, \& Vasseur, 2012). Conversely, dispersal limitation among isolated biological communities increases the strength of ecological drift and heightens the risk of local extinctions (Vellend, 2010). Hosts disconnected from the broader meta-community of conspecific microbiomes (Miller et al., 2018) - those in low density populations, at the fringes of populations, or experiencing social isolationmay be at greater risk of stochastic microbiome dysregulation. Evidence for dispersal limitation induced dysregulation of the microbiome has been demonstrated through experimental prevention of coprophagy in Brandt's voles (Bo et al., 2020). While similar concerns have been raised with respect to wildlife in captivity (McKenzie et al., 2017; Trevelline, Fontaine, Hartup, \& Kohl, 2019), this effect remains to be explicitly tested in free-living settings.

Dispersal limitation can feed ecological drift but so too can dietary and physiological factors which are often assumed to be deterministic. For example, different diets can exert divergent selective pressures, but can also differ in the energy made accessible to the microbiome and the diversity of metabolic niche space supported. Labile high energy diets may fail to support fibrolytic and cellulolytic niche-space in the microbiome (Oliphant \& Allen-Vercoe, 2019) and can destabilize microbial communities in a process similar to the paradox of enrichment (Coyte, Schluter, \& Foster, 2015; Rosenzweig, 1971). Similarly, while different host physiological states might select for different microbial functions (Foster, Schluter, Coyte, \& Rakoff-Nahoum, 2017), a loss of host homeostatic control among physiologically stressed hosts might result in community instability and greater stochastic variation (Zaneveld, McMinds, \& Vega Thurber, 2017). Microbiome $\beta$-dispersion, a 
measure of microbiome variance, is one indication of the relative strength of stochasticity. A second indication of stochasticity is the failure of communities to deviate from the stochastic expectations as predicted by null modelling approaches. Despite past misuse (for overview see: Narwani, Matthews, Fox, \& Venail, 2015), phylogenetic null modelling methods are valuable to consider alongside conventional $\beta$-diversity metrics, as traditional diversity metrics can be influenced by system gamma diversity and imbalances in alpha diversity between communities (Chase, Kraft, Smith, Vellend, \& Inouye, 2011; Gering \& Crist, 2002; Zhou \& Ning, 2017).

Here we directly contrast the ability of host physiology, habitat heterogeneity, and spatial measures to explain variation in the faecal bacterial microbiome of feral horses using 86 adult females from the closed population of Sable Island (Nova Scotia, Canada). Building on a comprehensive, long-term, detailed individual-based study of ecology and evolution for this population (Richard, Simpson, Medill, \& Mcloughlin, 2014), we apply a combination of conventional diversity analyses and null modeling approaches to evaluate the evidence for drift, dispersal, and niche-based processes. If environmental conditions and host physiology - sources of selective pressures which shape the microbiome - are more similar among populations than between populations or between species, then we would predict microbial dispersal patterns and ecological drift to play a comparably large role in shaping inter-individual microbiome variation within populations. Specifically, we predict that phylogeny-independent diversity measures will be most strongly influenced by spatial and social variables, reflecting microbial dispersal patterns. Conversely, we predicted that host physiology and local habitat heterogeneity would better explain variation in phylogeny-weighted metrics of microbiome diversity, reflecting different selective pressures imposed on host-associated microbiota between host physiological states or diets. Our study represents one of the first direct comparisons between environmental and spatial effects on host-associated microbiomes in the wild at a within population scale, with consideration offered to alternative ecological processes.

\section{2 | Methods}

\subsection{Study area and population}

Sable Island National Park Reserve, a crescent-shaped emergent sand bar, located $175 \mathrm{~km}$ off the east coast of Nova Scotia, Canada, spans $\sim 49 \mathrm{~km}$ and is $\sim 1.2 \mathrm{~km}$ at its widest point (Figure 1). The treeless island is dominated by marram grass (Ammophila breviligulata), common species in early-successional grasslands, occurring both in pure swards and in mixed communities alongside other species such as red fescue (Festuca rubra), beach pea (Lathyrus japonicus var. maritimus), and forbs such as meadow rue (Thalictrum pubescens ) or pearly everlasting (Anaphalis margaritacea). These grasslands comprise the most common vegetation association (Contasti, Tissier, Johnstone, \& McLoughlin, 2012). Sheltered by 10-30-m high dunes, in the interior of the island grasslands give way to late-successional mixed heath communities characterized by shrubs (e.g. common juniper [Juniperus communis var. megistocarpa], lowbush blueberry [Vaccinium angustifolium ], northern bayberry [Myrica pensylvanica ]), and the presence of an organic soil layer (Catiling, Lucas, \& Freedman, 2009; Tissier, Mcloughlin, Sheard, \& Johnstone, 2013). Dune height and vegetated landcover decrease as the island tapers towards its longitudinal extremes, where the semi-succulent forb sandwort (Honckenya peploides) dominates at the edges of dunes, and beach pea and seaside goldenrod (Solidago sempervirens ) are co-dominant with marram grass (Catiling et al., 2009; Tissier et al., 2013).

Introduced to the island circa 1750 and studied intensively by our research group since 2007 (Contasti, Van Beest, Vander Wal, \& McLoughlin, 2013; Gold et al., 2019), the feral horses are the only terrestrial mammal found on the island (Freedman, 2016). Since their introduction, the horses have remained unmanaged with very limited introgression from mainland domestic stock (most recently a single adult male in the 1930s; Welsh, 1975). The horse population, 550 individuals in 2014, declines sharply in density from west to east (Marjamäki, Contasti, Coulson, \& Mcloughlin, 2013). A polygynous mating system exists among the island's horses, characterized by mixed-sex social bands guarded by (often) a single dominant adult male (stallion) against mating attempts by other males. Females in the population invariably segregate across these mixedsex social bands which are comprised of the dominant stallion, adult females (mares), and subadult $(<3$ years of age) offspring (Regan et al., 2019). Bands can therefore be as small as 2 (one adult male and one 
female), although bands as large as 16 horses have been observed (Manning \& McLoughlin, 2017). Band memberships are stable across years but $67 \%$ of adult females were known to disperse to a different social band at least once during a 7-year period (Debeffe, Richard, Medill, Weisgerber, \& McLoughlin, 2015). Outside of social dispersal events, social bands traverse the landscape together but very rarely stray farther than $4000 \mathrm{~m}$ in either direction from the centre of their home-range during the summer. Most bands constrain their movements to $<2000 \mathrm{~m}$ from their home-range's centre (Rozen-Rechels et al., 2015). Bacterial dispersal between horses is expected to occur primarily between members of the same - or interacting - social bands and be facilitated by grooming, coprophagy, interactions with faecal territorial markers (stud piles), or the use of shared resources (Figure 2). Social dispersal of horses might likewise facilitate bacterial transmission between social bands over longer distances.

\subsection{Location and life history data}

Location data are collected during annual systematic surveys conducted between the months of JulySeptember. Each day (weather permitting) one of seven sections is surveyed on foot by one or multiple observers, and adjacent sections are not surveyed on consecutive days. Consequently, each section is typically surveyed once per week over a 6 to 8 weeks period. When horses are encountered, identifying photos are taken alongside location to the nearest $5 \mathrm{~m}$ using a handheld GPS device. Every year, each horse is sighted $5 \pm 2$ times ( $x \pm \mathrm{SD}$; Rozen-Rechels et al., 2015). Annual surveys across years allow us to track the birth, age, change in reproductive status, death, and social parentage of every individual.

\subsection{Sample collection and storage}

Since 2013, freshly voided feces have been routinely collected and archived. Samples are collected using sterile nitrile gloves which are inverted, sealed, and kept in insulated bags containing icepacks until returning to the laboratory on the same day (max $\sim 6 \mathrm{hrs}$ ). Subsamples ( ${ }^{\sim} 1-2$ grams each) are stored in cryotubes at $-20^{\circ} \mathrm{C}$ while on the island before transfer to long-term storage at $-80^{\circ} \mathrm{C}$ on the mainland at the end of each field season. For the present study we selected 86 fecal samples collected in 2014 between mid-July and early-September from 86 different adult females (mares) spanning 52 social bands (1-4 samples/band) which ranged from 3-12 horses in size. Each mare represented in the dataset was only sampled once. Ages ranged from 3-9+; 9-year-old mares might be over 9 years of age, as they were adults before the inaugural field season of the long-term study.

\subsection{Habitat Classification}

Habitat classifications were developed using Light Detection And Ranging (LiDAR) surveys and highresolution aerial photo in 2009 by the Applied Geomatics Research Group (Nova Scotia Community College, Middleton, Nova Scotia; van Beest et al. 2014). Non-vegetated habitat classes included bare sand, ocean, human structures (buildings with fenced perimeters), and freshwater ponds. Vegetated habitat classes were characterized by their dominant plant species: grassland (marram grass), heath (mixed juniper, crowberry, and blueberry), sandwort, and beach pea. Vegetated classes subcategorized into 'sparse' or 'dense' (e.g. sparse grassland and dense grassland) in original classification efforts were combined in our analyses.

To quantify individual variation in local environment, we calculated the area of habitat classes overlapping a 150-m radius circular buffer centred on the location of sample collection in $\mathrm{R}$ (v3.5.1). A 150-m radius buffer corresponds approximately to the observed median daily movement of horses in 2014 (positive skewed distribution, median: $108 \mathrm{~m} /$ day; median $317 \mathrm{~m} /$ day), and so is expected to coarsely reflect the types of environment, and therefore forage, encountered during the 24 hours preceding defecation. Habitat class variables were calculated as the area of a given habitat class relative to the total occupiable terrestrial area included within an individual's buffer (AreaBuffer - AreaBuilding- Area Ocean). Sandwort abundance was zero-inflated and non-normally distributed. Further, resource selection analysis of Sable Island horse foraging behaviour suggests horses actively select for sandwort when it is present, while other vegetated habitat classes are used in proportion to their abundance on the local landscape (personal communication K. Johnsen). For these statistical and biological reasons, sandwort was parameterized as 'present' or 'absent' in our analyses. Only vegetated habitat classes were parameterized in analyses to limit model inflation and 
avoid collinearity between terms.

\section{5 | Sequencing and Bioinformatics}

DNA from faecal samples were extracted using QIAgen's QIAamp PowerFecal DNA Kits. The protocol followed Qiagen's Kit Handbook with homogenization performed at full speed for 10 minutes using the $2 \mathrm{~mL}$ bead beating tubes provided with the kit $(0.7 \mathrm{~mm}$ Dry Garnet) and a Vortexed-Genie 2 fitted with Qiagen's Vortex Adapter (cat. No. 13000-V1-24). DNA extracts were quantified using the Qubit dsDNA BR Assay Kit and standardized to $20 \mathrm{ng} / \mathrm{uL}$ prior to PCR amplification. PCR and sequencing of the $\mathrm{v} 3-\mathrm{v} 4$ region of the 16S rRNA gene using the $341 \mathrm{~F} / 805 \mathrm{R}$ primers and sequencing on an Illumina MiSeq platform using the v3 chemistry was outsourced to the University of Calgary Centre for Health Genomics and Informatics.

Cutadapt v1.16 was used to remove primers from raw reads, while untrimmed reads were discarded (Martin, 2011). Trimmed reads were processed using dada2 v1.6 (Callahan et al., 2016), with only minor deviations from default parameters. Namely, sequences with a maximum expected error of two or greater, PhiX spikeins, and bases with a quality score of $<2$ were discarded using thefilterAndTrim command. Forward and reverse sequences were truncated to lengths of 250 and 200, respectively. Taxonomic assignment of amplicon sequence variants (ASVs) was performed using the dada2 implementation of the naive Bayesian classifier (Wang et al. 2007) and v132 of the SILVA database (Yilmaz et al., 2014). To further filter sequencing errors and reduce singleton noise prior to analysis, ASVs which were not represented by at least 1 count in 4 samples were removed (Knowles, Eccles, \& Baltrūnaitè, 2019). ASV sequences were aligned using MUSCLE with default parameters (Edgar, 2004) and a relaxed neighbour-joining method was used to construct a phylogenetic tree using the mothur implementation of clearcut (Kozich, Westcott, Baxter, Highlander, \& Schloss, 2013; Sheneman, Evans, \& Foster, 2006).

\section{6 | Diversity Analysis}

The number of ASVs (ASV richness) observed within a given community was used as a measure of $\alpha$ diversity. While $\alpha$-diversity indicates within community diversity, $\beta$-diversity indicates differences in community composition between communities. We analyzed two $\beta$-diversity metrics: Euclidean distances from a centred log-ratio transformed ASV dataset (Gloor, Macklaim, Pawlowsky-Glahn, \& Egozcue, 2017) and weighted UniFrac distance (Lozupone, Hamady, Kelley, \& Knight, 2007) of a rarefied ASV dataset (34,280 reads/sample; rarefaction curve: Figure S1, Supporting information). Both $\beta$-diversity metrics weight differences in the relative abundance of bacterial taxa between communities, but weighted UniFrac measures simultaneously weight bacteria phylogenetic relatedness. Finally, we also considered $\beta$-dispersion, calculated as the distance from each sample to the sample-set centroid in Euclidean or weighted UniFrac space (Anderson, Ellingsen, \& McArdle, 2006).

We evaluated the ability of spatiotemporal (Julian date, longitude and distance from the population's midpoint), host physiology (using age and parental status as proxies), and habitat class relative area to predict patterns in the described microbiome diversity measures. Julian date, longitude, and longitudinal distance from the population's centre were scaled to a mean of 0 and a standard deviation of 1 prior to analysis. The average longitude of all observations from the 2014 field season was used as a proxy for the population's centre. Age was coded as continuous data in 1-year increments, with a linear and $2^{\text {nd }}$ order polynomial fit considered in analyses, given a curvilinear relationship between gut microbiome diversity and age among humans (Yatsunenko et al., 2012). Parental status, shown to affect the microbiome in other systems (Amato et al., 2014), was coded as a dichotomous variable based on whether adult females were nursing a foal $(<1$ year old offspring) during the 2014 field survey.

For univariate diversity measures ( $\alpha$-diversity and $\beta$-dispersion), we used a multi-model inference approach implemented in the R package 'MuMIn' (Barton, 2009). A starting global general linear model was parameterized with the spatiotemporal, physiological, and environmental terms described above, without interactions. We determined parameter estimates and significance from conditional AICc averaging of models which had a $\Delta$ AICc $<3$ (Burnham \& Anderson, 2002; Grueber, Nakagawa, Laws, \& Jamieson, 2011). Patterns in $\beta$-diversity were analyzed using a backwards selection approach from PERMANOVA outputs, 
with the global model outputs reported in the Supporting information (vegan R package, adonis2() function, parameter by = 'margin'; Oksanen et al., 2019). Additionally, we ran a Mantel test to test for a correlation between spatial separation and $\beta$-diversity measures, and a univariate PERMANOVA to test for an effect of social band membership.

\section{7 | Testing for a phylogenetic signal}

Inferences made from phylogeny-informed null modeling approaches are predicated on the existence of a positive phylogenetic signal in species niche-space (Webb, Ackerly, McPeek, \& Donoghue, 2002); the notion that closely related species possess similar suites of traits and occupy similar niches (Tucker, Davies, Cadotte, \& Pearse, 2018). We tested for a phylogenetic signal with respect to abundance in the presence of sandwort using the R package phylosignal (Keck, Rimet, Bouchez, \& Franc, 2016). To approximate association with a sandwort-based diet, we estimated the abundance averaged niche space of each ASV. Briefly, abundances were relativized to the total sequence count for each ASV across all samples. Relative abundances among horses with access to sandwort were multiplied by 1 and relative abundances among horses without sandwort access were multiplied by -1 . The sum of these values within each ASV were assigned as a 'niche-score' for each ASV which varied continuously between -1 (ASV only present in horses with access to sandwort) and 1 (ASV only present in horses without access to sandwort). Sandwort was selected since: 1) different dietary components are expected to vary in their polysaccharide composition, thereby selecting for different microbial metabolic functions (Julliand \& Grimm, 2017) and 2) sandwort presence was observed in preceding analyses to be an important correlate of phylogeny-informed and phylogeny-independent $\beta$-diversity.

\section{8 | Null modelling within communities}

Like macro-ecological communities, the bacterial microbiome can be shaped by deterministic processes (e.g. selection), stochastic processes (e.g. ecological drift), and dispersal (Adair \& Douglas, 2017). If a given community is strongly shaped by selection acting on microbial traits, and microbial traits are phylogenetically conserved, then the phylogenetic structure of this community is expected to deviate from communities assembled through random chance (Webb et al., 2002). Conversely, if a community is strongly influence by ecological drift, then phylogenetic structure of this community is not expected to deviate strongly from null expectations.

To evaluate evidence for the strength of stochastic and deterministic processes in the Sable Island horse microbiome, we first calculated mean nearest taxon distances (MNTDs) using the R package picante (Kembel et al., 2010). MNTD is a measure of the average phylogenetic distance separating every taxon (in this instance ASV) in a community to its nearest neighbour and emphasizes diversity at the tips of a phylogenetic tree. For each horse microbiome, a MNTD null distribution was generated via 9999 randomly assembled communities of ASV richness equal to that of the observed community. Randomized communities were generated by re-shuffling taxa labels and relative abundances across a fixed phylogenetic tree comprising the gamma diversity observed across the entire sample-set. MNTDs were effect size-standardized $\left(\mathrm{MNTD}_{\text {ses }}\right)$ relative to the mean and standard deviation of the null distribution for a given community (Stegen, Lin, Konopka, \& Fredrickson, 2012). A $\mathrm{MNTD}_{\text {ses }}$ value smaller than -2 or greater than 2 indicate that a community is more phylogenetically clustered or over-dispersed than expected by chance, respectively. While these thresholds have historically been used to make inferences about the relative strength of competition versus environmental filtering (Cavender-Bares, Kozak, Fine, \& Kembel, 2009), thought experiments and mixed results from the literature demonstrate such cut-offs are overly simplistic and can lead to a misattribution of pattern to ecological process (Mayfield \& Levine, 2010). We instead considered only the magnitude of phylogenetic departure from stochastic expectations $\left(\left|\mathrm{MNTD}_{\mathrm{ses}}\right|\right)$ in a mixed model inference.

\section{9 | Null modelling between communities}

The same principles which underlie the use of phylogenetic null modelling within a given community, can be used to infer possible mechanisms for the variation observed between communities. For between community comparisons, nearest taxon distances are instead calculated between an ASV in one microbiome and its closest relative in a second microbiome ( $\beta$ mean nearest taxon distance $[\beta$ MNTD]) (Stegen et al., 2012). As 
above, we standardized $\beta$ MNTDs by the mean and standard deviation of a null distribution created via 999 randomly assembled community pairs $\left(\beta M N T D_{\text {ses }}\right)$. Positive $\beta M N T D_{\text {ses }}$ indicate that two communities are more phylogenetically disparate than would be expected given random sampling of a given pool of gamma diversity. Conversely, negative $\beta_{M N T D}$ ses indicate that two communities are more phylogenetically similar than would be expected. Assuming taxa niche-spaces and phylogenies are correlated, then positive and negative $\beta M_{N T D}$ ses values can indicate that the differences or similarities observed between two communities might be the result of differential or similar selective pressures, respectively (Stegen et al., 2012). $\left|\beta M N T D_{\text {ses }}\right|$ values of $<2$ are conventionally considered to indicate that inter-community differences might be the result of dispersal patterns or ecological drift, as phylogenetic patterns observed between communities do not differ greatly from those of randomly assembled community pairs. We analyzed $\beta$ MNTD ${ }_{\text {ses }}$ using a PERMANOVA parameterized identically to the $\beta$-diversity analyses described above. Additionally, we ran a mantel test to test for a correlation between spatial separation and $\beta M N T D_{\text {ses }}$ values, and a univariate PERMANOVA to test for an effect of social band. For all nearest taxon analyses, we used a phylogenetic tree made ultrametric $(\lambda=1)$ using the chronos() function from the R package 'ape'.

Finally, we also used a phylogeny-independent extension of this null modeling framework by calculating Raup-Crick Bray $_{(}\left(\mathrm{RC}_{\text {bray }}\right.$ ) values (Chase et al., 2011; Stegen et al., 2013). Rather than consider greater- or less- than-expected phylogenetic similarities between communities, $\mathrm{RC}_{\mathrm{bray}}$ values indicate whether taxa cooccur at similar abundances more or less often than expected independent of their phylogenetic relatedness (Lowe \& McPeek, 2014; Stegen et al., 2013). Among communities which do not show strong phylogenetic deviations from null expectations, $\mathrm{RC}_{\text {bray }}$ estimates $<-0.95$ indicate that taxa co-occur at similar abundances between communities more frequently than would be expected by chance alone, one indication of homogenizing dispersal. $\mathrm{RC}_{\text {bray }}$ estimates $>0.95$ indicate that taxa co-occur between communities less often than would be expected given random expectations, indicating dispersal limitation. Finally, $\left|\mathrm{RC}_{\mathrm{bray}}\right|<0.95$ indicate that rates of taxa co-occurrence do not differ from null expectations, suggesting possible ecological drift. Null distributions used to make comparisons were created via 9999 community pairs created through

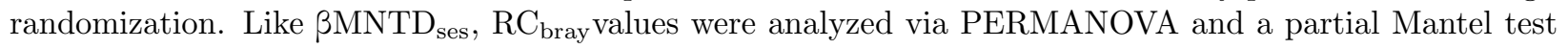
was used to test for a correlation between $\mathrm{RC}_{\text {bray }}$ values and longitudinal separation, after controlling for $\beta \mathrm{MNTD}_{\text {ses }}$ values.

\section{3 | Results}

\subsection{Summary of the Sable Island Horse Microbiome}

We used a $16 \mathrm{~S}$ amplicon sequencing approach to characterize the bacterial microbiome of faecal samples collected from 86 adult females of the Sable Island feral horse population. Sequencing resulted in an average of 51,480 quality assembled reads per sample (rarefied to 34,280 reads for all analyses other than those which used centred-log ratio transformed count tables). A total of 3,767 ASVs were detected in the population, although the average horse hosted $817 \pm 11$ SE ASVs, and only 2 ASVs were observed in all 86 horses.

The average Sable Island horse microbiome was comprised of Ruminococcaceae $(15 \% \pm 4 \%$ SD mean relative abundance), Lachnospiraceae $(13 \% \pm 3 \%)$, Prevotellaceae $(10 \% \pm 2 \%)$, Spirochaetaceae $(9 \% \pm 3 \%)$, Fibrobacteriaceae $(9 \% \pm 4 \%)$, Rikenellaceae $(8 \% \pm 3 \%)$, and three Bacteroidales families (p-251-o5: $9 \% \pm$ $4 \%, \mathrm{~F} 082: 3 \% \pm 2 \%, \mathrm{RF} 16: 2 \% \pm 1 \%$ ). An additional 56 families comprised $13 \% \pm 3 \%$ of rarefied reads, while the remaining $9 \% \pm 2 \%$ of sequences could not be assigned to family; almost half of these unassigned reads were identified as members of the order WCHB1-41 within the newly described class, Kiritimatiellae (Figure S2, Supporting information). Alpha diversity (ASV richness) decreased by $45 \pm 12 \mathrm{SE}$ with every 1 standard deviation increase in longitude $(p<0.01)$. Horses with access to sandwort also had $137 \pm 35 \mathrm{SE}$ fewer ASVs than those without access to sandwort $(p<0.01)$, while mares without foals had $52 \pm 20 \mathrm{SE}$ fewer ASVs than mares with foals $(p=0.01$; Figure 3$)$. The full model averaging output can be found in Table S1 of the Supporting information.

\section{$3.2 \mid \Pi \eta \psi \lambda o \gamma \varepsilon \nu \psi-I \nu \delta \varepsilon \pi \varepsilon \nu \delta \varepsilon \nu \tau \beta-\Delta \iota \varepsilon \rho \sigma \iota \tau \psi$}

Euclidean distance, a phylogeny-independent $\beta$-diversity distance measure, was significantly correlated with 
Julian date $\left(R^{2}=0.02, p<0.01\right)$, longitude $\left(R^{2}=0.02, p<0.01\right)$, distance from the population's centre $\left(R^{2}=0.02, p<0.01\right)$, and sandwort availability $\left(R^{2}=0.02, p<0.01\right)$. The full PERMANOVA output is reported in Table S2 of the Supporting information. Sandwort presence appeared to underlie the primary ecological gradient in these communities based on PCA visualization (Figure 4A). Furthermore, Euclidean distances were correlated with the longitudinal distance separating horses $\left(r_{\text {pearson }}=0.37, p<0.01\right.$; Figure 4B). Additionally, in a univariate PERMANOVA, social band membership was significantly correlated with Euclidean distances $\left(R^{2}=0.66, p<0.01\right)$. Multi-model inference analysis of $\beta$-dispersion, a measure of $\beta$-diversity between an individual horse's microbiome and the horse population's theoretical average microbiome, indicated a negative correlation with longitude $(p=0.01)$ and a positive correlation with distance from the centre of the population ( $p=0.03$; Table S3, Supporting information).

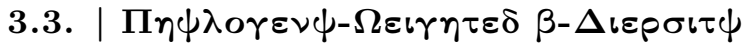

Phylogeny weighted $\beta$-diversity (weighted UniFrac distance) was significantly correlated with Julian date $\left(R^{2}=0.02, p=0.01\right)$, longitude $\left(\mathrm{R}^{2}=0.03, p=0.01\right)$, sandwort presence $\left(R^{2}=0.03, p<0.01\right)$, and beach pea availability $\left(R^{2}=0.02, p=0.02\right.$; Table $\mathrm{S} 4$, Supporting information). A positive correlation was again observed between the longitudinal distance separating horses and weighted UniFrac distance (Mantel test: $\left.r_{\text {pearson }}=0.33, p<0.01\right)$. Similarly, in a univariate PERMANOVA, band membership was found to be significantly correlated with weighted UniFrac distance $\left(R^{2}=0.69, p<0.01\right)$. Log-transformed weighted UniFrac $\beta$-dispersion was greater among horses with access to sandwort $(p<0.01)$ but negatively correlated with beach pea abundance ( $p=0.01$, Table S5, Supporting information). Of note, $\beta$-dispersion in weighted UniFrac space trended towards being higher among mares with foals than those without, although this effect was marginally non-significant $(p=0.06)$.

\section{4 | Ecological Null Modeling}

We detected a positive signal over short phylogenetic distances in relation to sandwort availability $(p<$ $0.05, r=0.02$; Figure S3, Supporting information). Of the physiological, environmental, and spatial terms considered, only parental status $(p=0.03)$ was associated with non-random patterns of phylogenetic dispersion. Namely mares with foals had higher $\left|\mathrm{MNTD}_{\text {ses }}\right|$ values (Table S6, Supporting information). Based on between-sample comparisons, communities were more often phylogenetically conserved $\left(\beta M N T D_{\text {ses }}<0\right)$ than they were phylogenetically disparate $\left(\beta \mathrm{MNTD}_{\text {ses }}>0\right)$ but usually did not deviate in expected phylogenetic similarity from pairs of randomly assembled communities $\left(\left|\beta M N T D_{\text {ses }}\right|<2\right)$.

$\beta \mathrm{MNTD}_{\text {ses }}$ values were correlated with Julian date $\left(R^{2}=0.03, p<0.01\right)$, sandwort presence $\left(\mathrm{R}^{2}=0.07\right.$, $p<0.01)$, beach pea availability $\left(R^{2}=0.03, p=0.02\right)$, heathland availability $\left(R^{2}=0.03, p=0.01\right)$, and grassland availability $\left(R^{2}=0.02, p=0.04\right.$; Table S7, Supporting information). In the absence of sandwort, $\beta \mathrm{MNTD}_{\text {ses }}$ values appeared to be negatively correlated with average grassland availability (Figure 5), but positively correlated with average heath availability (Figure S4A, Supporting information); conversely, $\beta \mathrm{MNTD}_{\text {ses }}$ values were greater when sandwort was present and appeared to be negatively correlated with average Julian date. In contrast, the absolute magnitude of phylogenetic deviation from stochastic expectations $\left(\left|\beta M N T D_{\text {ses }}\right|\right)$ was correlated with beach pea availability $\left(R^{2}=0.05, p<0.01\right)$, longitude $\left(\mathrm{R}^{2}=\right.$ $0.05, p=0.04)$, and parental status $\left(R^{2}=0.03, p=0.03\right.$; Table S8, Supporting information). Specifically, $\left|\beta M N T D_{\text {ses }}\right|$ values appeared to be positively correlated with beach pea availability (Figure S4B, Supporting information) as well as average longitude, and greater among mares with foals than mares without foals (Figure S4C, Supporting information). No significant correlation was observed between longitudinal separation and $\beta \mathrm{MNTD}_{\text {ses }}$ after controlling for sandwort presence (partial Mantel test: $p=0.68$ ). Similarly, no effect of band membership on $\beta$ MNTD $_{\text {ses }}$ was observed (PERMANOVA: $p=0.45$ ).

Approximately $14 \%$ of $\beta \mathrm{MNTD}_{\text {ses }}$ were beyond 2 standard deviations of the randomized null distributions. Of the remaining $\sim 86 \%$ of pairwise comparisons, $\sim 97 \%$ had corresponding $\mathrm{RC}_{\text {bray }}$ values exceeding 0.95 , which signals greater ASV turnover than expected under ecological drift alone, a pattern suggestive of dispersal limitation. Based on PERMANOVA analysis, $\mathrm{RC}_{\text {bray }}$ values were correlated with longitude $\left(R^{2}=0.02, p\right.$ $<0.01)$, distance from the centre of the population $\left(R^{2}=0.02, p<0.01\right)$, sandwort presence $\left(R^{2}=0.01\right.$, 
$p=0.04)$, beach pea availability $\left(R^{2}=0.01, p=0.04\right)$, and Julian date. $\left(\mathrm{R}^{2}=0.02, p<0.01\right.$; Table S9, Supporting information). Additionally, in a univariate PERMANOVA, band membership was significantly correlated with $\mathrm{RC}_{\text {bray }}$ values $\left(R^{2}=0.65, p<0.01\right)$. Furthermore, $\mathrm{RC}_{\text {bray }}$ values were positively correlated with the distance separating horses even after controlling for $\beta \mathrm{MNTD}_{\text {ses }}$ values (partial Mantel test: $r_{\text {pearson }}$ $=0.17, p<0.01$; Figure 6A), but negatively correlated with average longitude and lower among members of the same band than between members of different bands (Figure $6 \mathrm{~B}$ ).

\section{4 | Discussion}

Accounting for spatial processes in our system was integral to explaining observed patterns of microbiome variation. Longitude explained variation in almost every microbiome diversity measure considered. Alpha diversity declined from west to east, and longitude was correlated with both Euclidean and weighted UniFrac measures of $\beta$-diversity. Unmeasured environmental variables may account for these patterns; however, plant communities representing the Sable Island horses' primary forage were present in our analyses. Furthermore, if environmental selective pressures acting on the microbiome were spatially autocorrelated, we would have expected co-occurring horse microbiomes to be more phylogenetically similar, and distant horses to be more phylogenetically disparate, than expected by chance. Contrary to these expectations, we did not observe a positive correlation between $\beta \mathrm{MNTD}_{\text {ses }}$ and the distance separating horses. Further, the microbiomes of horses in the west and towards the longitudinal extremes of the island tended to be further from the population average. The significance of spatial terms in PERMANOVA analysis of Euclidean distances may therefore derive partly from differences in community variance rather than differences in average community structure.

Host genetics, and thus indirectly the physiological environment with which microbes directly interact, might explain some of the spatial variation in microbiome variance. Based on microsatellite data, Sable Island horse heterozygosity is higher in the east (Lucas, McLoughlin, Coltman, \& Barber, 2009) which is where we also observed lower microbiome alpha diversity and beta-dispersion when compared to horses in the west. Evidence from captive and wild mammalian systems has shown microbiome alpha diversity to be negatively correlated with host heterozygosity (Grosser et al., 2019; Wadud Khan, Zac Stephens, Mohammed, Round, \& Kubinak, 2019). Similarly, an effect of population-level heterozygosity has been reported on the bacterial microbiome of free-living bighorn sheep (Couch et al., 2020). The homozygosity implicit of inbred hosts might restrict their immunological complexity (Potts \& Wakeland, 1993; Reid, Arcese, \& Keller, 2003), thereby also restricting the dexterity with which host's recruit and "leash" (see Foster, Schluter, Coyte, \& Rakoff-Nahoum, 2017) their microbial communities, perhaps allowing for greater stochastic variation between individuals. Alternatively, $\mathrm{F}_{\text {st }}$ values suggest population sub-structuring between the east and west (Lucas et al., 2009), therefore genetic differences between horses might explain why the microbiome differs across the island's length. For example, among free-living house mice genetic similarity along a latitudinal gradient was a better predictor of microbiome similarity than spatial proximity (Suzuki et al., 2019). Genetic variation among Sable Island horses expressed as phenotypic variation could therefore drive microbiome variance across the island's longitude (Alberdi, Aizpurua, Bohmann, Zepeda-Mendoza, \& Gilbert, 2016).

While we cannot rule out a role for host genetics, in the present absence of data informative for testing this, bacterial dispersal limitation between horses provides the most parsimonious explanation of observed patterns. For example, we observed an apparent positive correlation between the proximity of horses and the similarity of their microbiome in Euclidean space (independent of similarities in local environment). A similar relationship was observed with respect to weighted UniFrac distances, however no positive relationship was observed among phylogeny-informed null modeling approaches $\left(\beta M N T D_{\text {ses }}\right)$. Assuming bacterial niche space and phylogeny are non-independent, these patterns suggest that the decrease in microbiome similarity with spatial separation was not due primarily to differences in selective pressures across space. Conversely, the positive relationship between spatial separation and $\mathrm{RC}_{\text {bray }}$ values suggest dispersal limitation may occur over relatively short spatial scales. Evidence for dispersal limitation may be unsurprising given a zero-inflated ASV count table; of 3767 ASVs, only 2 were detected in all horses and only 441 were present in at least half of the horses. 
In addition to a positive correlation with spatial separation, $\mathrm{RC}_{\text {bray }}$ values were negatively correlated with average longitude, suggesting greater dispersal limitation among horses in the west than the east. This was unexpected since horse population density, which could facilitate bacterial dispersal between individuals, decreases from west to east (Marjamäki et al., 2013). However, while multiple above-ground ponds can be found in the west, horses in the east must crater through sand to access freshwater (Contasti et al., 2012). Horse-excavated wells are semi-permanent within a season and visited by multiple social bands but are only accessible to 1-2 horse at a time (Figure 2D). Prolonged occupancy of an area of social band overlap, and bottlenecked access to a communal consumable resource, could catalyze bacterial dispersal despite low population densities in the east. Similar host aggregation due to patchy resource distribution on urban landscapes facilitates disease transmission in wildlife (Bradley \& Altizer, 2007); the same aggregative effect could as easily facilitate transmission of commensal and mutualistic microbiota.

Bacterial dispersal between horses undoubtedly occurs; however, it may be largely restricted to between individuals within the same, or closely interacting, social bands. Social band membership was correlated with both Euclidean and weighted UniFrac $\beta$-diversity; however, microbiome phylogenetic diversity $\left(\beta \mathrm{MNTD}_{\text {ses }}\right)$ was no more similar between members of the same band than between members of different bands when compared to null expectations, offering little support for homogenizing selection as the mechanism for the effect of band membership on the microbiome. $\mathrm{RC}_{\text {bray }}$ values, which were lower between members of the same band than between horses of different bands, suggests bacterial dispersal limitation as a primary cause for the observed effect of social band. This interpretation is consistent with Antwis, Lea, Unwin, \& Shultz (2018) who report an effect of band identity and inter-band connectivity on microbiome $\beta$-diversity among three large social bands of feral Welsh ponies. Similar differences in band connectivity might explain why, above and beyond parameterized environmental terms, distance from the population's centre was correlated with Euclidean $\beta$-diversity and $\beta$-dispersion. No relationship was observed with respect to $\beta M N T D_{\text {ses }}$ but $\mathrm{RC}_{\text {bray }}$ values were positively correlated with average distance from the centre of the population. Horses on the edges of the population - those more poorly connected within the population's microbiome meta-community (Miller et al., 2018) - might be vulnerable to erosion of microbiome diversity through microbial extinctions and exacerbated ecological drift. Together these results support recent suggestions of the importance of inter-host dispersal in maintaining the 'social microbiome' in free-living populations (Sarkar et al., 2020).

Phylogeny-informed measures of diversity were often better explained by local plant community composition than spatial terms. Horses with sandwort in their 150-m radius buffer had lower alpha diversity and differed in both phylogeny-informed (Euclidean) and phylogeny-independent (weighted UniFrac) $\beta$-diversity measures. The intuitive explanation is that plant community availability reflects dietary composition, and different dietary components differ in the functions required to metabolize component polysaccharides (David et al., 2014; Julliand \& Grimm, 2017). However, among pairwise comparisons in which sandwort was present for at least one horse, microbiomes were no more phylogenetically disparate than expected by chance (higher $\left.\beta \mathrm{MNTD}_{\text {ses }}\right)$. By comparison, the microbiomes of horses without access to sandwort tended to be more phylogenetically similar. Conversely, grassland and beach pea dominated habitat classes were negatively correlated with $\beta \mathrm{MNTD}_{\text {ses }}$, while heath (only present where sandwort was absent) appeared positively correlated with $\beta \mathrm{MNTD}_{\text {ses }}$. Therefore, phylogenetic patterns most consistent with homogenizing selection on the microbiome were observed when sandwort and heath were absent, but beach pea and marram grass were abundant; with reversed conditions, phylogenetic similarities did not deviate far from stochastic expectations.

Increased evidence for stochasticity may stem from the fact that sandwort, forbs and small graminoids - the primary horse forage in heathland habitat - possess lower neutral detergent fibre (NDF) when compared to beach pea and marram grass (personal communication K. Johnsen; Lee, 2018). NDF is a coarse measure of plant lignin, hemicellulose, and cellulose (Mongeau \& Brassard, 1982); compounds which many herbivores are obligately reliant on their gastrointestinal microbiota to metabolize (Costa \& Weese, 2012). The low NDF observed in sandwort and heathland forbs may alleviate the horses' reliance on their intestinal microbiota, allowing them to directly absorb nutrients from a relatively labile diet. Loss of dietary complexity constrains fibrolytic and cellulolytic niche-space in the microbiome which can manifest as reductions in bacterial gene richness (Cotillard et al., 2013) or alpha diversity (Schnorr et al., 2014). Conversely, high fibre forage (e.g. 
marram grass and beach pea) can facilitate complex microbial symbioses in which different species specialize on metabolizing different biochemical compounds, and in doing so, create by-products to be absorbed by the host or further metabolized by other microbiota (Oliphant \& Allen-Vercoe, 2019). The reduction in alpha diversity observed in horses with access to sandwort mirror the effects of low dietary fibre manipulations in domestic horses (Julliand \& Grimm, 2017). When compared to with marram grass and beach pea, sandwort might represent a reduction in the carbon source complexity accessible to the microbiome, a property thought to have a stabilizing effect on the microbiome (Coyte et al., 2015). A diet containing sandwort might not select for different microbial functions, so much as fail to support fibrolytic niche-space supported by high fibre diets, leading to species extirpation and greater ecological drift within individual host microbiomes (Deehan $\&$ Walter, 2016). This could also explain the greater variability in weighted UniFrac $\beta$-diversity among horses with access to sandwort and the decrease in dispersion in response to beach pea availability. These results highlight how dietary derived microbiome variation might not always be the result of strong differential selective pressures between communities; the relationship between dietary complexity and ecological drift must also be considered (Adair \& Douglas, 2017; Zhou \& Ning, 2017).

Parental status was more strongly correlated with measures of microbiome variance, rather than mean community structure. Specifically, mares with foals had microbiomes which were a) more diverse, b) marginally less variable in weighted UniFrac space, c) less randomly phylogenetically dispersed (greater $\left|\mathrm{MNTD}_{\text {ses }}\right|$ ), and d) further from phylogenetic null expectations of random community assembly (higher $\left|\beta M N T D_{\text {ses }}\right|$ ) when compared to mares without foals. Effects of parturition and maternal status on microbiome alpha and $\beta$-diversity have been observed in livestock (Lima et al., 2015) and wildlife (Amato et al., 2014). Although, to our knowledge, a difference in $\beta$-dispersion between parental states has not previously been reported. Myriad changes to maternal physiology during pregnancy and parturition are likely partly responsible for microbiome differences during birth and child-rearing (Huang et al., 2019; Nuriel-Ohayon, Neuman, \& Koren, 2016). In addition to these physiological changes, maternal care among mammals, especially lactation, saddles mothers with a heavy energetic burden (Dufour \& Sauther, 2002; Scantlebury, Russell, McIlrat, Speakman, \& Clutton-Brock, 2002). To meet higher energetic demands, hosts may become increasingly reliant on their microbiomes (Amato et al., 2014); especially in species, such as horses, which are obligately reliant on their gut microbiomes for nutrient uptake (Costa \& Weese, 2012). Therefore, during periods of high energetic demand hosts might be forced to enforce stronger control on the microbiome to maximize metabolic efficiency. For example, in laboratory mice, postpartum dampening of bi-directionality in the host-microbiome relationship is evidenced by attenuated bacterial driven immunomodulation (Mu et al., 2019). We suggest that hosts facing a high energetic burden might keep their microbial constituents on a "tighter leash" than those with a lower energetic demand (Foster et al., 2017). Within host species, host physiological variation might in many cases act to facultatively constrain $\beta$-dispersion, rather than drive changes in $\beta$-diversity, although patterns of the former are often overlooked (Zaneveld et al., 2017). The reverse causal relationship could also explain the patterns observed, whereby a diverse microbiome under tight host control signals better host health and therefore greater likelihood of carrying a foal to term.

Overall, the bacterial microbiome of Sable Island horses is dominated by clades of fibrolytic taxa, including Ruminococcaceae, Lachnospiraceae, Prevotellaceae, and Fibrobacteraceae (Biddle, Stewart, Blanchard, \& Leschine, 2013; Esquivel-Elizondo, Ilhan, Garcia-Peña, \& Krajmalnik-Brown, 2017; Spain, Forsberg, \& Krumholz, 2011). Spirochaetaceae and Kiritimatiellae are also present at modest relative abundances; however, their metabolic niches are currently less well characterized. These results are consistent with findings from domestic, feral, and wild horse systems (Antwis et al., 2018; Costa et al., 2015; Metcalf et al., 2017) and a comprehensive comparison of wild and domestic equid species (Edwards et al., 2020). Unlike previous studies, however, we detected no effect of age, likely because we constrained sampling to horses of at least 3 years of age, and the horse microbiome appears to reach maturation after $\sim 1$ year (Antwis et al., 2018; De La Torre et al., 2019; Metcalf et al., 2017).

We characterized the bacterial microbiome of 86 mares from the feral horse population of Sable Island (Nova Scotia, Canada) and contrasted the ability of spatiotemporal, physiological, and diet-linked environmental variables to explain microbiome variation. Phylogeny-independent measures of diversity were best explained 
by spatial variables while phylogeny-informed measures were generally better characterized by host physiology (parental status) and measures of local habitat heterogeneity; however, despite statistical significance, these variables explained only nominal variation in overall $\beta$-diversity. Only the longitudinal distance separating horses and social band membership explained what could be considered substantive variation, and yet, much of the variation in the Sable Island horse microbiome remained unexplained. In context, our results suggest a predominant importance of bacterial dispersal and ecological drift in shaping faecal microbiome variation among Sable Island horses. Our findings are relevant to the study of wildlife microbiome variation: clearly data on the spatial distribution of hosts should be collected, even at the within-population scale, alongside metrics of individual-based environmental variation. Further, when a response of the microbiome to environmental or physiological variation is observed, deterministic processes must not be assumed as the sole causal process.

\section{Acknowledgements}

We thank the numerous students, research assistants and volunteers who contributed to sample collection and processing. In-kind and logistical support was provided by the Fisheries and Oceans Canada (DFO), Canada Coast Guard, the Bedford Institute of Oceanography (DFO Science), Environment Canada, Parks Canada Agency, Maritime Air Charters Limited (Sable Aviation), and Sable Island Station (Meteorological Service of Canada). Funding was provided by the Margaret Gunn Endowment for Animal Research, the L. David Dubé and Heather Ryan Veterinary Health and Research Fund, the Natural Sciences and Engineering Research Council of Canada (Discovery Grants Nos 2019-04388 to JP, 2016-06459 to PDM), and the Canada Foundation for Innovation (Leaders Opportunity Grant No. 25046). SG and AH were supported by scholarships from the University of Calgary Department of Ecosystem and Public Health and the O'Brien Centre for the Bachelor of Health Sciences. MRS was supported variously by an NSERC Vanier scholarship, Alberta Innovates scholarship, and Izaak Walton Killam scholarship while completing the research contained herein. Sample collection and laboratory analyses were performed under Parks Canada Agency Research and Collections Permit SINP-2013-2014, University of Saskatchewan Animal Care Protocol 20090032, and University of Calgary Animal Care Protocol AC18-0078.

\section{References}

Adair, K. L., \& Douglas, A. E. (2017). Making a microbiome: the many determinants of host-associated microbial community composition. Current Opinion in Microbiology , 35 , 23-29. doi:10.1016/j.mib.2016.11.002

Alberdi, A., Aizpurua, O., Bohmann, K., Zepeda-Mendoza, M. L., \& Gilbert, M. T. P. (2016). Do vertebrate gut metagenomes confer rapid ecological adaptation? Trends in Ecology and Evolution ,31 (9), 689-699. doi:10.1016/j.tree.2016.06.008

Amato, K. R., Leigh, S. R., Kent, A., Mackie, R. I., Yeoman, C. J., Stumpf, R. M., .. Garber, P. A. (2014). The role of gut microbes in satisfying the nutritional demands of adult and juvenile wild, black howler monkeys (Alouatta pigra ). American Journal of Physical Anthropology , 155 , 652-664. doi:10.1002/ajpa.22621

Anderson, M. J., Ellingsen, K. E., \& McArdle, B. H. (2006). Multivariate dispersion as a measure of beta diversity. Ecology Letters , 9 (6), 683-693. doi:10.1111/j.1461-0248.2006.00926.x

Antwis, R. E., Lea, J. M. D., Unwin, B., \& Shultz, S. (2018). Gut microbiome composition is associated with spatial structuring and social interactions in semi-feral Welsh Mountain ponies. Microbiome ,6 (1), 207. doi:10.1186/s40168-018-0593-2

Balasubramaniam, K., Beisner, B., Guan, J., Vandeleest, J., Fushing, H., Atwill, E., \& McCowan, B. (2018). Social network community structure and the contact-mediated sharing of commensal E. coli among captive rhesus macaques (Macaca mulatta ). PeerJ , 1-30. doi:10.7717/peerj.4271

Bartoń, K. (2009). MuMIn: multi-model inference. R package. Retrieved from https://cran.rproject.org $/$ package $=$ MuMIn 
Biddle, A., Stewart, L., Blanchard, J., \& Leschine, S. (2013). Untangling the genetic basis of fibrolytic specialization by Lachnospiraceae and Ruminococcaceae in diverse gut communities.Diversity , 5 (3), 627640. doi:10.3390/d5030627

Bo, T. B., Zhang, X. Y., Kohl, K. D., Wen, J., Tian, S. J., \& Wang, D. H. (2020). Coprophagy prevention alters microbiome, metabolism, neurochemistry, and cognitive behavior in a small mammal. ISME Journal . doi:10.1038/s41396-020-0711-6

Bradley, C. a, \& Altizer, S. (2007). Urbanization and the ecology of wildlife diseases. Trends in Ecology $\mathscr{E}$ Evolution , 22 (2), 95-102. doi:10.1016/j.tree.2006.11.001

Burnham, K. P., \& Anderson, D. R. (2002). Avoiding pitfalls when using information-theoretic methods. The Journal of Wildlife Management, 66 (3), 912-918.

Callahan, B. J., Mcmurdie, P. J., Rosen, M. J., Han, A. W., Johnson, A. J. A., \& Holmes, S. P. (2016). dada2: high-resolution sample inference from illumina amplicon data, 13 (7). doi:10.1038/nMeth.3869

Catiling, P., Lucas, Z., \& Freedman, B. (2009). Plants and insects new to Sable Island, Nova Scotia. Canadian Field-Naturalist ,123 (2), 141-145. doi:10.22621/cfn.v123i2.692

Cavender-Bares, J., Kozak, K. H., Fine, P. V. A., \& Kembel, S. W. (2009). The merging of community ecology and phylogenetic biology.Ecology Letters , 12 (7), 693-715. doi:10.1111/j.1461-0248.2009.01314.x

Chase, J. M., Kraft, N. J. B., Smith, K. G., Vellend, M., \& Inouye, B. D. (2011). Using null models to disentangle variation in community dissimilarity from variation in $\alpha$-diversity. Ecosphere ,2 (2). doi:10.1890/ES1000117.1

Contasti, A. L., Tissier, E. J., Johnstone, J. F., \& McLoughlin, P. D. (2012). Explaining spatial heterogeneity in population dynamics and genetics from spatial variation in resources for a large herbivore.PLoS ONE , 7 (10). doi:10.1371/journal.pone.0047858

Contasti, A. L., Van Beest, F. M., Vander Wal, E., \& McLoughlin, P. D. (2013). Identifying hidden sinks in growing populations from individual fates and movements: The feral horses of Sable Island. Journal of Wildlife Management, 77 (8), 1545-1552. doi:10.1002/jwmg.625

Costa, M. C., Silva, G., Ramos, R. V., Staempfli, H. R., Arroyo, L. G., Kim, P., \& Weese, J. S. (2015). Characterization and comparison of the bacterial microbiota in different gastrointestinal tract compartments in horses. Veterinary Journal , 205 (1), 74-80. doi:10.1016/j.tvjl.2015.03.018

Costa, Marcio C, \& Weese, J. S. (2012). The equine intestinal microbiome. Animal Health Research Reviews , 13 (1), 121-128. doi:10.1017/S1466252312000035

Cotillard, A., Kennedy, S. P., Kong, L. C., Prifti, E., Pons, N., Le Chatelier, E., .. L Layec, S. (2013). Dietary intervention impact on gut microbial gene richness. Nature , 500 (7464), 585-588. doi:10.1038/nature12480

Couch, C. E., Arnold, H. K., Crowhurst, R. S., Jolles, A. E., Sharpton, T. J., Witczak, M. F., .. Beechler, B. R. (2020). Bighorn sheep gut microbiomes associate with genetic and spatial structure across a metapopulation. Scientific Reports , 10 (1), 1-10. doi:10.1038/s41598-020-63401-0

Coyte, K. Z., Schluter, J., \& Foster, K. R. (2015). The ecology of the microbiome: networks, competition, and stability. Science ,350 (6261), 663-666. doi:10.1126/science.aad2602

Crowley, P. H. (1981). Dispersal and the Stability of Predator-Prey Interactions. The American Naturalist , 118 (5), 673-701. doi:10.1086/283861

David, L. A., Maurice, C. F., Carmody, R. N., Gootenberg, D. B., Button, J. E., Wolfe, B. E., .. Turnbaugh, P. J. (2014). Diet rapidly and reproducibly alters the human gut microbiome. Nature ,505 (7484), 559-563. doi:10.1038/nature12820 
De La Torre, U., Henderson, J. D., Furtado, K. L., Pedroja, M., Elenamarie, O., Mora, A., .. Mienaltowski, M. J. (2019). Utilizing the fecal microbiota to understand foal gut transitions from birth to weaning. PLoS ONE , 14 (4), 1-18. doi:10.1371/journal.pone.0216211

Debeffe, L., Richard, E., Medill, S. A., Weisgerber, J. N., \& McLoughlin, P. D. (2015). Costs of social dispersal in a polygynous mammal. Behavioral Ecology , 26 (6), 1476-1485. doi:10.1093/beheco/arv092

Deehan, E. C., \& Walter, J. (2016). The fiber gap and the disappearing gut microbiome: implications for human nutrition. Trends in Endocrinology and Metabolism , 27 (5), 239-242. doi:10.1016/j.tem.2016.03.001

Dufour, D. L., \& Sauther, M. L. (2002). Comparative and evolutionary dimensions of the energetics of human pregnancy and lactation.American Journal of Human Biology , 14 (5), 584-602. doi:10.1002/ajhb.10071

Edgar, R. C. (2004). MUSCLE: multiple sequence alignment with high accuracy and high throughput. Nucleic Acids Research ,32 (5), 1792-7. doi:10.1093/nar/gkh340

Edwards, J. E., Shetty, S. A., van den Berg, P., Burden, F., van Doorn, D. A., Pellikaan, W. F., ... Smidt, H. (2020). Multi-kingdom characterization of the core equine fecal microbiota based on multiple equine (sub)species. Animal Microbiome , 2 (1), 6. doi:10.1186/s42523-020-0023-1

Esquivel-Elizondo, S., Ilhan, Z. E., Garcia-Peña, E. I., \& Krajmalnik-Brown, R. (2017). Insights into butyrate production in a controlled fermentation system via gene predictions. MSystems ,2 (4), 1-13. doi:10.1128/msystems.00051-17

Foster, K. R., Schluter, J., Coyte, K. Z., \& Rakoff-Nahoum, S. (2017). The evolution of the host microbiome as an ecosystem on a leash.Nature , 548 (7665), 43-51. doi:10.1038/nature23292

Fountain-Jones, N. M., Clark, N. J., Kinsley, A. C., Carstensen, M., Forester, J., Johnson, T. J., .. Craft, M. E. (2020). Microbial associations and spatial proximity predict North American moose (Alces alces) gastrointestinal community composition.Journal of Animal Ecology , 89 (3), 817-828. doi:10.1111/13652656.13154

Freedman, B. (2016). Sable Island : Explorations in Ecology \& Biodiversity (2nd ed.). Markham, Toronto: Fitzhenry \& Whiteside.

Gering, J. C., \& Crist, T. O. (2002). The alpha-beta-regional relationship: Providing new insights into local-regional patterns of species richness and scale dependence of diversity components.Ecology Letters , 5 (3), 433-444. doi:10.1046/j.1461-0248.2002.00335.x

Gloor, G. B., Macklaim, J. M., Pawlowsky-Glahn, V., \& Egozcue, J. J. (2017). Microbiome datasets are compositional: and this is not optional.Frontiers in Microbiology , 8 , 2224. doi:10.3389/fmicb.2017.02224

Goertz, S., de Menezes, A. B., Birtles, R. J., Fenn, J., Lowe, A. E., MacColl, A. D. C., .. Taylor, C. H. (2019). Geographical location influences the composition of the gut microbiota in wild house mice (Mus musculus domesticus ) at a fine spatial scale. PLoS ONE , 14 (9), 1-16. doi:10.1371/journal.pone.0222501

Gold, S., Regan, C. E., McLoughlin, P. D., Gilleard, J. S., Wilson, A. J., \& Poissant, J. (2019). Quantitative genetics of gastrointestinal strongyle burden and associated body condition in feral horses.International Journal for Parasitology: Parasites and Wildlife ,9 , 104-111. doi:10.1016/j.ijppaw.2019.03.010

Greyson-Gaito, C. J., Bartley, T. J., Cottenie, K., Jarvis, W. M. C., Newman, A. E. M., \& Stothart, M. R. (2020). Into the wild: Microbiome transplant studies need broader ecological reality. Proceedings of the Royal Society B: Biological Sciences , 287 (1921). doi:10.1098/rspb.2019.2834

Grosser, S., Sauer, J., Paijmans, A. J., Caspers, B. A., Forcada, J., Wolf, J. B. W., \& Hoffman, J. I. (2019). Fur seal microbiota are shaped by the social and physical environment, show mother-offspring similarities and are associated with host genetic quality. Molecular Ecology , 28 (9), 2406-2422. doi:10.1111/mec.15070 
Grueber, C. E., Nakagawa, S., Laws, R. J., \& Jamieson, I. G. (2011). Multimodel inference in ecology and evolution: challenges and solutions. Journal of Evolutionary Biology , 24, 699-711. doi:10.1111/j.14209101.2010.02210.x

Huang, X., Gao, J., Zhao, Y., He, M., Ke, S., Wu, J., ... Huang, L. (2019). Dramatic remodeling of the gut microbiome around parturition and its relationship with host serum metabolic changes in sows. Frontiers in Microbiology , 10 , 1-12. doi:10.3389/fmicb.2019.02123

Julliand, V., \& Grimm, P. (2017). The impact of diet on the hindgut microbiome. Journal of Equine Veterinary Science , 52 , 23-28. doi:10.1016/j.jevs.2017.03.002

Kartzinel, T. R., Hsing, J. C., Musili, P. M., Brown, B. R. P., \& Pringle, R. M. (2019). Covariation of diet and gut microbiome in African megafauna. Proceedings of the National Academy of Sciences , 201905666. doi:10.1073/pnas.1905666116

Keck, F., Rimet, F., Bouchez, A., \& Franc, A. (2016). phylosignal: an R package to measure, test, and explore the phylogenetic signal.Ecology and Evolution , 6 (9), 2774-2780. doi:10.1002/ece3.2051

Kembel, S. W., Cowan, P. D., Helmus, M. R., Cornwell, W. K., Morlon, H., Ackerly, D. D., .. Webb, C. O. (2010). Picante: R tools for integrating phylogenies and ecology. Bioinformatics ,26 (11), 1463-1464. doi:10.1093/bioinformatics/btq166

Knowles, S. C. L., Eccles, R. M., \& Baltrūnaitè, L. (2019). Species identity dominates over environment in shaping the microbiota of small mammals. Ecology Letters, ele.13240. doi:10.1111/ele.13240

Kohl, K. D., Varner, J., Wilkening, J. L., \& Dearing, M. D. (2018). Gut microbial communities of American pikas (Ochotona princeps ): evidence for phylosymbiosis and adaptations to novel diets. Journal of Animal Ecology , 87 (2), 323-330. doi:10.1111/1365-2656.12692

Kozich, J. J., Westcott, S. L., Baxter, N. T., Highlander, S. K., \& Schloss, P. D. (2013). Development of a dual-index sequencing strategy and curation pipeline for analyzing amplicon sequence data on the MiSeq Illumina sequencing platform. Applied and Environmental Microbiology , 79 (17), 5112-5120. doi:10.1128/AEM.01043-13

Lee, M. A. (2018). A global comparison of the nutritive values of forage plants grown in contrasting environments. Journal of Plant Research , 131 (4), 641-654. doi:10.1007/s10265-018-1024-y

Lima, F. S., Oikonomou, G., Lima, S. F., Bicalho, M. L. S., Ganda, E. K., de Oliveira Filho, J. C., ... Bicalho, R. C. (2015). Prepartum and postpartum rumen fluid microbiomes: Characterization and correlation with production traits in dairy cows. Applied and Environmental Microbiology , 81 (4), 1327-1337. doi:10.1128/AEM.03138-14

Linnenbrink, M., Wang, J., Hardouin, E. A., Künzel, S., Metzler, D., \& Baines, J. F. (2013). The role of biogeography in shaping diversity of the intestinal microbiota in house mice. Molecular Ecology ,22 (7), 1904-1916. doi:10.1111/mec.12206

Lowe, W. H., \& McPeek, M. A. (2014). Is dispersal neutral? Trends in Ecology and Evolution , 29 (8), 444-450. doi:10.1016/j.tree.2014.05.009

Lozupone, C. A., Hamady, M., Kelley, S. T., \& Knight, R. (2007). Quantitative and qualitative beta diversity measures lead to different insights into factors that structure microbial communities. Applied and Environmental Microbiologyicrobiology , 73 (5), 1576-1585. doi:10.1128/AEM.01996-06

Lucas, Z. L., McLoughlin, P. D., Coltman, D. W., \& Barber, C. (2009). Multiscale analysis reveals restricted gene flow and a linear gradient in heterozygosity for an island population of feral horses. Canadian Journal of Zoology , 87 (4), 310-316. doi:10.1139/Z09-019

Manning, J. A., \& McLoughlin, P. D. (2017). Environmental and demographic drivers of male mating success 
vary across sequential reproductive episodes in a polygynous breeder. Ecology and Evolution , 9 (9), 51065117. doi:10.1002/ece3.5066

Marjamäki, P. H., Contasti, A. L., Coulson, T. N., \& Mcloughlin, P. D. (2013). Local density and group size interacts with age and sex to determine direction and rate of social dispersal in a polygynous mammal.Ecology and Evolution , 3 (9), 3073-3082. doi:10.1002/ece3.694

Martin, M. (2011). Cutadapt removes adapter sequences from high-throughput sequencing reads. EMBnet , $17(1), 10-12$.

Mayfield, M. M., \& Levine, J. M. (2010). Opposing effects of competitive exclusion on the phylogenetic structure of communities.Ecology Letters , 13 (9), 1085-1093. doi:10.1111/j.1461-0248.2010.01509.x

McCord, A. I., Chapman, C. A., Weny, G., Tumukunde, A., Hyeroba, D., Klotz, K., .. Goldberg, T. (2014). Fecal microbiomes of non-human primates in western Uganda reveal species-specific communities largely resistant to habitat perturbation. American Journal of Primatology, 76 . doi:10.1002/ajp.22238

McKenzie, V. J., Song, S. J., Delsuc, F., Prest, T. L., Oliverio, A. M., Korpita, T. M., .. Knight, R. (2017). The effects of captivity on the mammalian gut microbiome. Integrative and Comparative Biology , 57 (4), 690-704. doi:10.1093/icb/icx090

Metcalf, J. L., Song, S. J., Morton, J. T., Weiss, S., Seguin-Orlando, A., Joly, F., .. Orlando, L. (2017). Evaluating the impact of domestication and captivity on the horse gut microbiome.Scientific Reports , 7 (1), 15497. doi:10.1038/s41598-017-15375-9

Miller, E. T., Svanback, R., \& Bohannan, B. J. M. (2018). Microbiomes as metacommunities: understanding host-associated microbes through metacommunity ecology. Trends in Ecology $6 \mathcal{6}$ Evolution ,33 (12), 926-935. doi:10.1016/j.tree.2018.09.002

Moeller, A. H., Suzuki, T. A., Lin, D., Lacey, E. A., Wasser, S. K., \& Nachman, M. W. (2017). Dispersal limitation promotes the diversification of the mammalian gut microbiota. Proceedings of the National Academy of Sciences of the United States of America , 114 (52), 13768-13773. doi:10.1073/pnas.1700122114

Mongeau, R., \& Brassard, R. (1982). Determination of neutral detergent fiber in breakfast cereals: pentose, hemicellulose, cellulose and lignin content. Journal of Food Science , 47 (2), 550-555. doi:10.1111/j.13652621.1982.tb10121.x

Mu, Q., Cabana-Puig, X., Mao, J., Swartwout, B., Abdelhamid, L., Cecere, T. E., ... Luo, X. M. (2019). Pregnancy and lactation interfere with the response of autoimmunity to modulation of gut microbiota.Microbiome , 7 (1), 1-13. doi:10.1186/s40168-019-0720-8

Narwani, A., Matthews, B., Fox, J., \& Venail, P. (2015). Using phylogenetics in community assembly and ecosystem functioning research.Functional Ecology , 29 (5), 589-591. doi:10.1111/1365-2435.12431

Nuriel-Ohayon, M., Neuman, H., \& Koren, O. (2016). Microbial changes during pregnancy, birth, and infancy. Frontiers in Microbiology ,7 , 1-13. doi:10.3389/fmicb.2016.01031

Oksanen, J., Kindt, R., Legendre, P., O'Hara, B., Simpson, G. L., Solymos, P. M., .. Wagner, H. (2008). vegan: Community Ecology Package. $R$ Package . Retrieved from https://cran.r-project.org/package=vegan

Oliphant, K., \& Allen-Vercoe, E. (2019). Macronutrient metabolism by the human gut microbiome: Major fermentation by-products and their impact on host health. Microbiome , 7 (1), 1-15. doi:10.1186/s40168019-0704-8

Potts, W. K., \& Wakeland, E. K. (1993). Evolution of MHC genetic diversity: a tale of incest, pestilence and sexual preference.Trends in Genetics , 9 (12), 408-412. doi:10.1016/0168-9525(93)90103-O

Regan, C. E., Tuke, L. A., Colpitts, J., McLoughlin, P. D., Wilson, A. J., \& Poissant, J. (2019). Evolutionary quantitative genetics of juvenile body size in a population of feral horses reveals sexually antagonistic 
selection. Evolutionary Ecology , 33 (4), 567-584. doi:10.1007/s10682-019-09988-x

Reid, J. M., Arcese, P., \& Keller, L. F. (2003). Inbreeding depresses immune response in song sparrows (Melospiza melodia): Direct and inter-generational effects. Proceedings of the Royal Society B: Biological Sciences , 270 (1529), 2151-2157. doi:10.1098/rspb.2003.2480

Ren, T., Boutin, S., Humphries, M. M., Dantzer, B., Gorrell, J. C., Coltman, D. W., .. Wu, M. (2017). Seasonal, spatial, and maternal effects on gut microbiome in wild red squirrels. Microbiome ,5 (163), 1-14. doi:10.1186/s40168-017-0382-3

Richard, E., Simpson, S. E., Medill, S. A., \& Mcloughlin, P. D. (2014). Interacting effects of age, density, and weather on survival and current reproduction for a large mammal. Ecology and Evolution ,4 (19), 3851-3860. doi:10.1002/ece3.1250

Rosenzweig. (1971). Paradox of enrichment: destabilization of exploitation ecosystems in ecological time. Science, $385-387$.

Rothschild, D., Weissbrod, O., Barkan, E., Kurilshikov, A., Korem, T., Zeevi, D., ... Segal, E. (2018). Environment dominates over host genetics in shaping human gut microbiota. Nature ,555 (7695), 210-215. doi:10.1038/nature25973

Rozen-Rechels, D., van Beest, F. M., Richard, E., Uzal, A., Medill, S. A., \& Mcloughlin, P. D. (2015). Density-dependent, central-place foraging in a grazing herbivore: Competition and tradeoffs in time allocation near water. Oikos , 124 (9), 1142-1150. doi:10.1111/oik.02207

Sarkar, A., Harty, S., Johnson, K. V. A., Moeller, A. H., Archie, E. A., Schell, L. D., .. Burnet, P. W. J. (2020). Microbial transmission in animal social networks and the social microbiome. Nature Ecology and Evolution . doi:10.1038/s41559-020-1220-8

Scantlebury, M., Russell, A. F., McIlrat, G. M., Speakman, J. R., \& Clutton-Brock, T. H. (2002). The energetics of lactation in cooperatively breeding meerkats Suricata suricatta.Proceedings of the Royal Society B: Biological Sciences ,269 (1505), 2147-2153. doi:10.1098/rspb.2002.2108

Schnorr, S. L., Candela, M., Rampelli, S., Centanni, M., Consolandi, C., Basaglia, G., ... Crittenden, A. N. (2014). Gut microbiome of the Hadza hunter-gatherers. Nature Communications , 5 . doi:10.1038/ncomms4654

Sheneman, L., Evans, J., \& Foster, J. A. (2006). Clearcut: A fast implementation of relaxed neighbor joining. Bioinformatics ,22 (22), 2823-2824. doi:10.1093/bioinformatics/btl478

Spain, A. M., Forsberg, C. W., \& Krumholz, L. R. (2011).Fibrobacteraceae fam. nov. Bergey's Manual of Systematics of Archaea and Bacteria . doi:10.1002/9781118960608.fbm00110

Stegen, J. C., Lin, X., Fredrickson, J. K., Chen, X., Kennedy, D. W., Murray, C. J., .. Konopka, A. (2013). Quantifying community assembly processes and identifying features that impose them. The ISME Journal , 7 (11), 2069-2079. doi:10.1038/ismej.2013.93

Stegen, J. C., Lin, X., Konopka, A. E., \& Fredrickson, J. K. (2012). Stochastic and deterministic assembly processes in subsurface microbial communities. The ISME Journal , 6 (9), 1653-1664. doi:10.1038/ismej.2012.22

Stothart, M. R., Palme, R., \& Newman, A. E. M. (2019). It's what's on the inside that counts: stress physiology and the bacterial microbiome of a wild urban mammal. Proceedings of the Royal Society B,286 , 1-9. doi:10.1098/rspb.2019.2111

Suzuki, T. A., Phifer-Rixey, M., Mack, K. L., Sheehan, M. J., Lin, D., Bi, K., \& Nachman, M. W. (2019). Host genetic determinants of the gut microbiota of wild mice. Molecular Ecology , 28 (13), 111. doi:10.1111/mec.15139 
Teyssier, A., Matthysen, E., Hudin, N. S., de Neve, L., White, J., \& Lens, L. (2020). Diet contributes to urban-induced alterations in gut microbiota: Experimental evidence from a wild passerine.Proceedings of the Royal Society B: Biological Sciences ,287 . doi:10.1098/rspb.2019.2182

Tissier, E. J., Mcloughlin, P. D., Sheard, J. W., \& Johnstone, J. F. (2013). Distribution of vegetation along environmental gradients on Sable Island, Nova Scotia. Ecoscience, 20 (4), 361-372. doi:10.2980/20-4-3616

Trevelline, B. K., Fontaine, S. S., Hartup, B. K., \& Kohl, K. D. (2019). Conservation biology needs a microbial renaissance: A call for the consideration of host-associated microbiota in wildlife management practices. Proceedings of the Royal Society B: Biological Sciences , 286 . doi:10.1098/rspb.2018.2448

Tucker, C. M., Davies, T. J., Cadotte, M. W., \& Pearse, W. D. (2018). On the relationship between phylogenetic diversity and trait diversity.Ecology , 99 (6), 1473-1479. doi:10.1002/ecy.2349

Tung, J., Barreiro, L. B., Burns, M. B., Grenier, J.-C., Lynch, J., Grieneisen, L. E., .. Archie, E. A. (2015). Social networks predict gut microbiome composition in wild baboons. ELife ,4 (e05224), 1-18. doi:10.7554/eLife.05224.001

Vellend, M. (2010). Conceptual synthesis in community ecology.Quarterly Review of Biology , 85 (2), 183206. doi:10.1086/652373

Wadud Khan, M. A., Zac Stephens, W., Mohammed, A. D., Round, J. L., \& Kubinak, J. L. (2019). Does MHC heterozygosity influence microbiota form and function? PLoS ONE , 14 (5), 1-23. doi:10.1371/journal.pone.0215946

Webb, C. O., Ackerly, D. D., McPeek, M. A., \& Donoghue, M. J. (2002). Phylogenies and community ecology. Annual Review of Ecology and Systematics , 33 , 475-505. doi:10.1146/annurev.ecolsys.33.010802.150448

Welsh, D. (1975). Population, behavioural and grazing ecology of the horses of Sable Island. Dalhousie University.

White, J., Mirleau, P., Danchin, E., Mulard, H., Hatch, S. A., Heeb, P., \& Wagner, R. H. (2010). Sexually transmitted bacteria affect female cloacal assemblages in a wild bird. Ecology Letters ,13 (12), 1515-1524. doi:10.1111/j.1461-0248.2010.01542.x

Yaari, G., Ben-Zion, Y., Shnerb, N. M., \& Vasseur, D. A. (2012). Consistent scaling of persistence time in metapopulations.Ecology , 93 (5), 1214-1227. doi:10.1890/11-1077.1

Yatsunenko, T., Rey, F. E., Manary, M. J., Trehan, I., Dominguez-Bello, M. G., Contreras, M., .. Gordon, J. I. (2012). Human gut microbiome viewed across age and geography. Nature ,486 (7402), 222. doi:10.1038/nature11053

Yilmaz, P., Parfrey, L. W., Yarza, P., Gerken, J., Pruesse, E., Quast, C., .. Glockner, F. O. (2014). The SILVA and "All-species Living Tree Project (LTP)" taxonomic frameworks. Nucleic Acids Research , 42 , 643-648. doi:10.1093/nar/gkt1209

Zaneveld, J. R., McMinds, R., \& Vega Thurber, R. (2017). Stress and stability: applying the Anna Karenina principle to animal microbiomes.Nature Microbiology , 2 (9), 17121. doi:10.1038/nmicrobiol.2017.121

Zhou, J., \& Ning, D. (2017). Stochastic community assembly: does it matter in microbial ecology? Microbiology and Molecular Biology Reviews , 81 (4), 2-17. doi:10.1128/MMBR

\section{Data Accessibility}

Upon acceptance all metadata files, $\mathrm{R}$ scripts, and bioinformatics pipelines will be deposited on Dryad. All raw 16S rRNA gene reads will be archived on the NCBI Sequence Read Archive (SRA).

\section{Author Contributions}


JP, PDM and AJW secured research funding. JP and PDM led sample collection and laboratory analysis. AH and SG completed bioinformatic processing. JP and MRS designed the study. MRS completed analyses and led the writing efforts. RJG contributed habitat classification data, created map visualization, and wrote the description and discussion of the island's vegetation. All authors contributed to the writing of the final submitted manuscript.

\section{Figures}

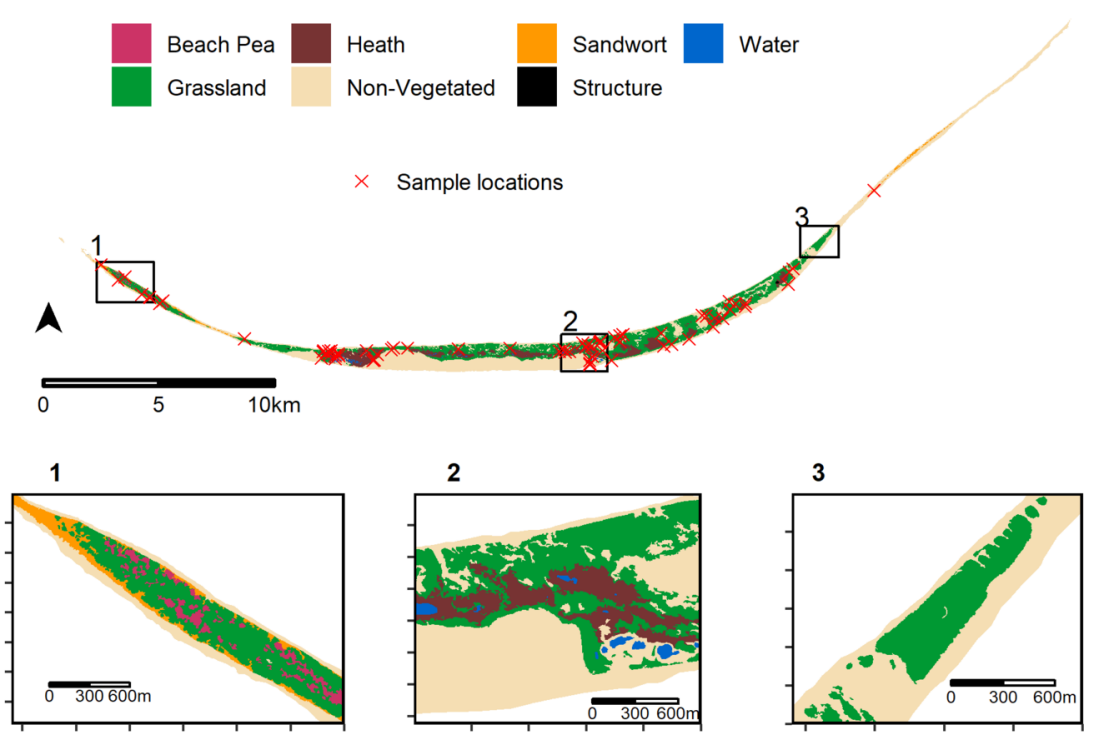

Figure 1: A map of Sable Island National Park Reserve, Nova Scotia (Canada). Habitat classes were delineated through a combination of Light Detection And Ranging (LiDAR) surveys, high-resolution aerial photography, and ground truthing. X marks the spot of collection for the fecal samples used in this study. Insets 1,2 , and 3 demonstrate habitat class heterogeneity across the island's length. 

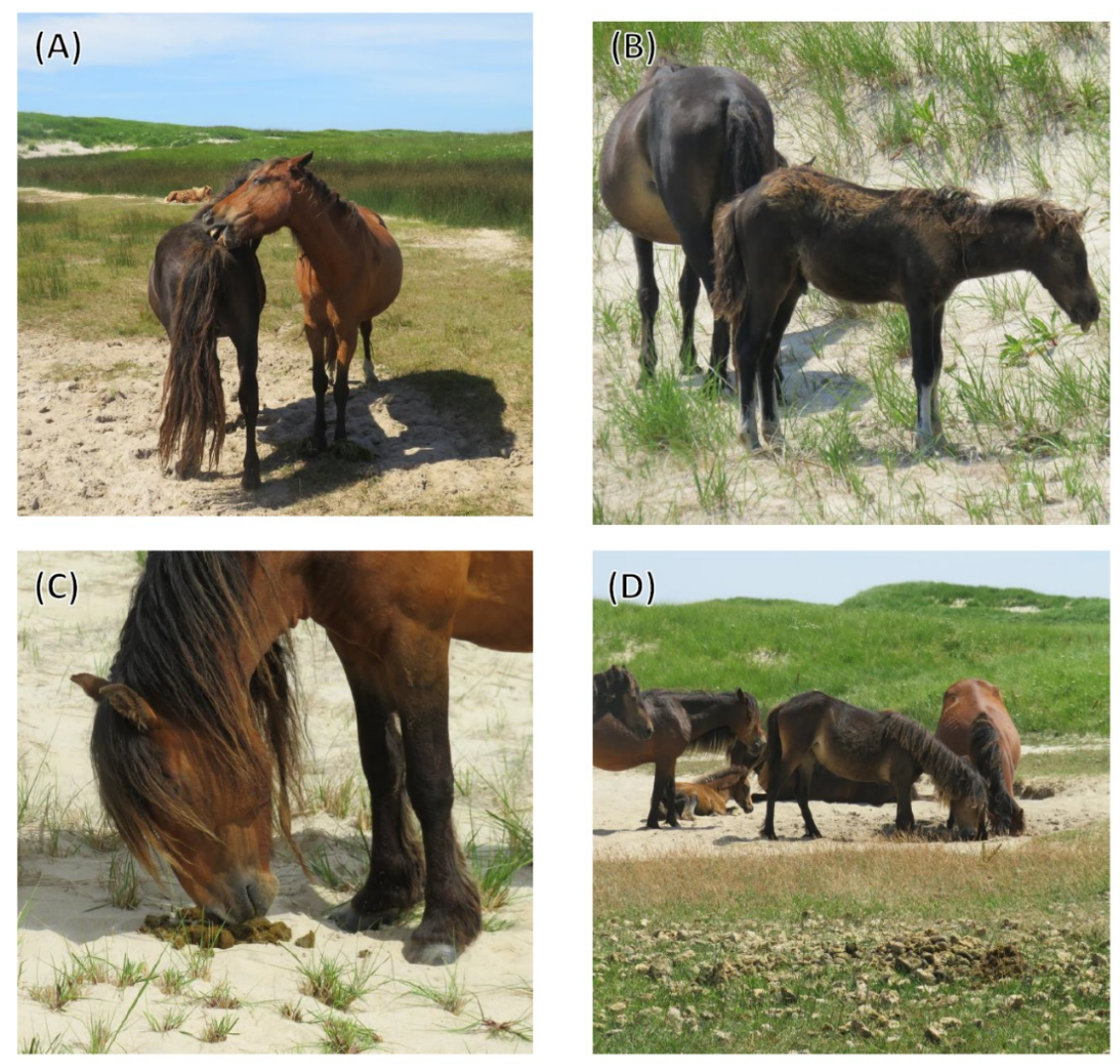

Figure 2: Putative mechanisms of bacterial dispersal between Sable Island horses: (A) social grooming [pictured: social band stallion (left) and mare (right) engaged in reciprocal grooming], (B) coprophagy, the consumption of feces [pictured: a foal (foreground) consuming the faeces of its mother (background)], (C) interaction with the faeces of band members or faecal territory markers (stud pile) [pictured: band stallion scenting faeces from a social band mare], (D) aggregation of social bands at communal resources [pictured: horses standing in - and drinking from - an excavated freshwater well (background) immediately adjacent to a fecal stud pile (foreground)]. Photos (CMason R. Stothart. 


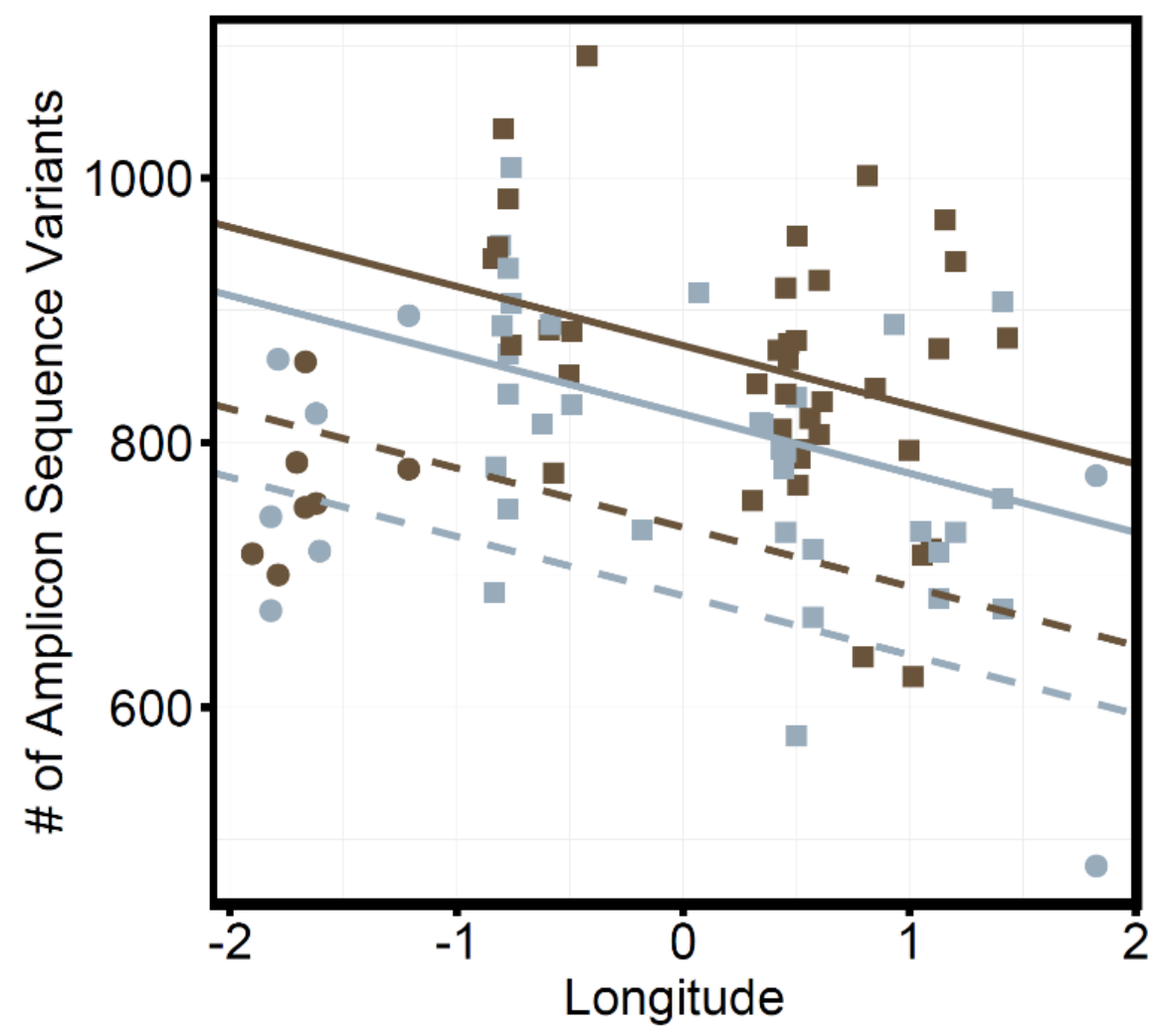

Figure 3: A scatter plot of Sable Island horse microbiome ASV richness versus standardized longitude coloured by parental status and shaped by sandwort presence in a 150-m radius buffer surrounding the point of sample collection. Points are shaped by whether sandwort is present (circle: ${ }^{*}$ ) or absent (square: ) and coloured by whether mares were with a foal (brown: ${ }^{*}$ ) or without a foal (light blue: ${ }^{*}$ ). Lines are parameterized by estimates from multi-model inference model averaging, typed by sandwort presence (present, dashed: —; absent, solid:- ) and coloured by parental status (with a foal, brown:- ; without a foal, light blue: - ). 

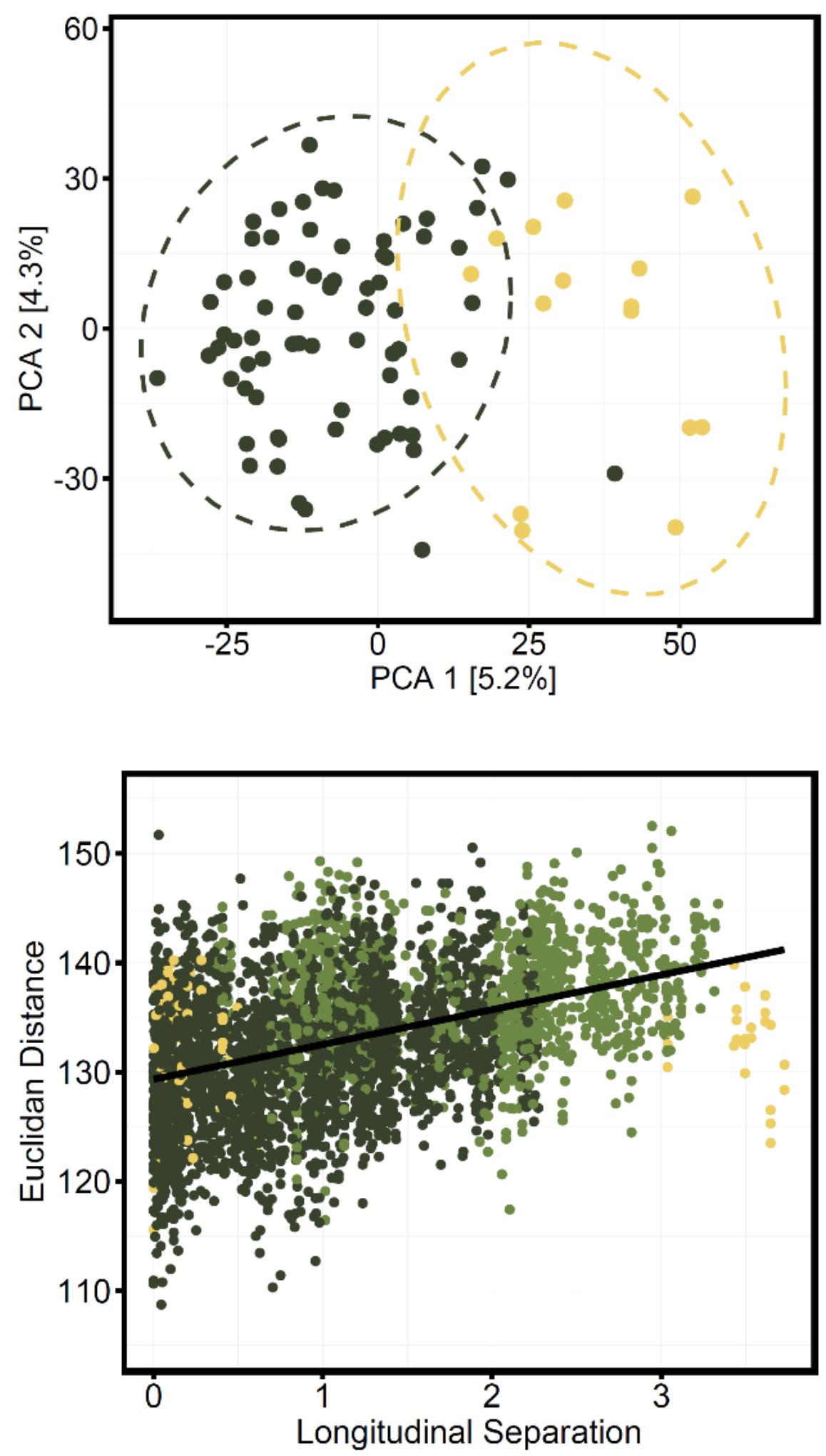

Figure 4: The Sable Island horse faecal microbiome $\beta$-diversity (Euclidean distance centred log-transformed 
counts) visualized in (A) a PCA coloured by sandwort availability in 150-m radius buffers surrounding the point of sample collection (absent, dark green: ${ }^{*}$, present, gold: ${ }^{*}$ ) and (B) a scatterplot of Euclidean distance and the longitudinal distance separating horses, points coloured depending on whether 150-m spatial buffer contained sandwort for neither horse (dark green: *), only one horse (green: *), or both horses (gold: *). For ease of plot visualization, a single point was omitted from panel '(B)' corresponding to two horses of the same social band sampled at the same location (longitudinal separation $=0$, Euclidean distance $=69$ ) .

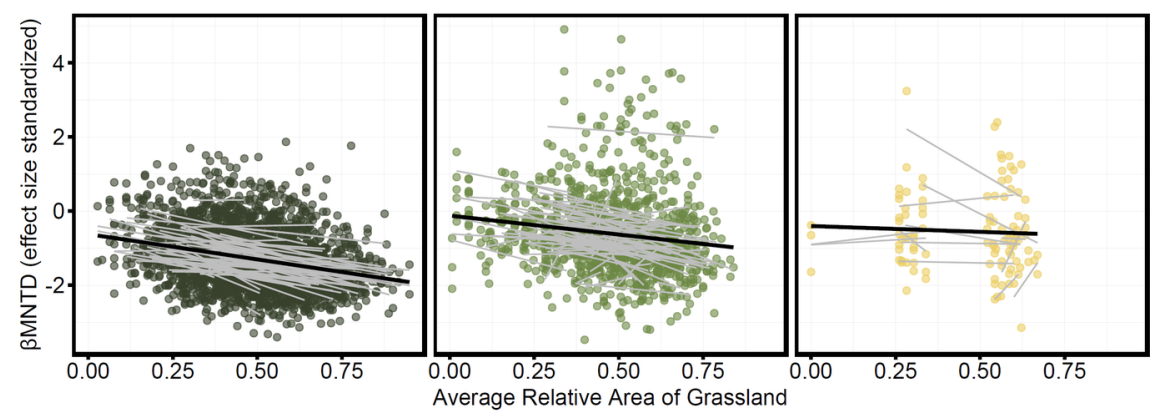

Figure 5: Scatterplot of pairwise average relative area of grassland within 150-m radius buffers centred on point of sample collection versus effect size standardized $\beta$ mean nearest taxon distance between horse pairs. Plot facetted by sandwort presence within 150-m radius buffer (absent for both horses, dark green: *; present for only one horse, green: *; present for both horses, gold: *). Black lines denote the lines of best fit, grey lines are lines of best fit group by individual one of the pairwise comparisons. 


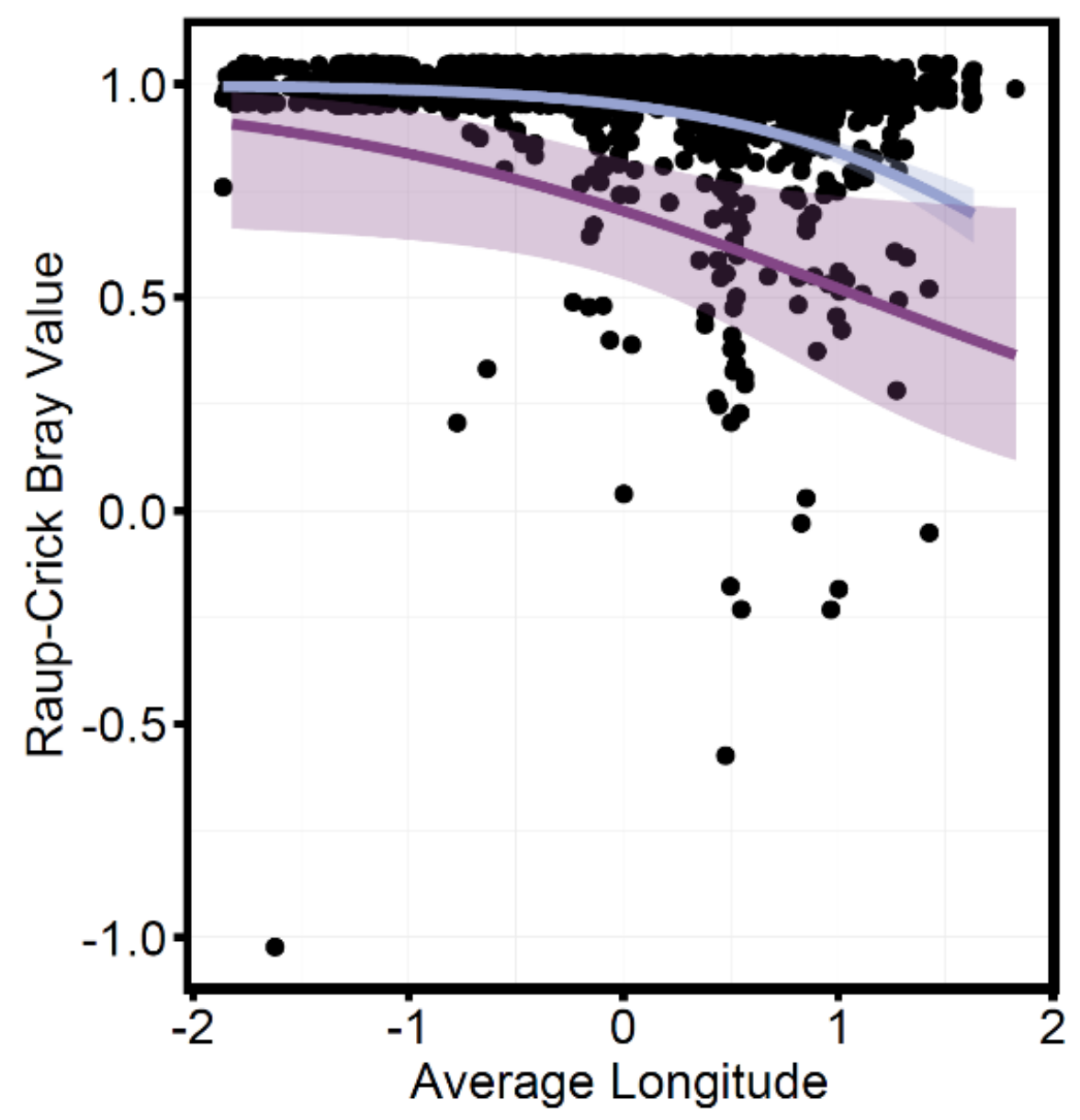




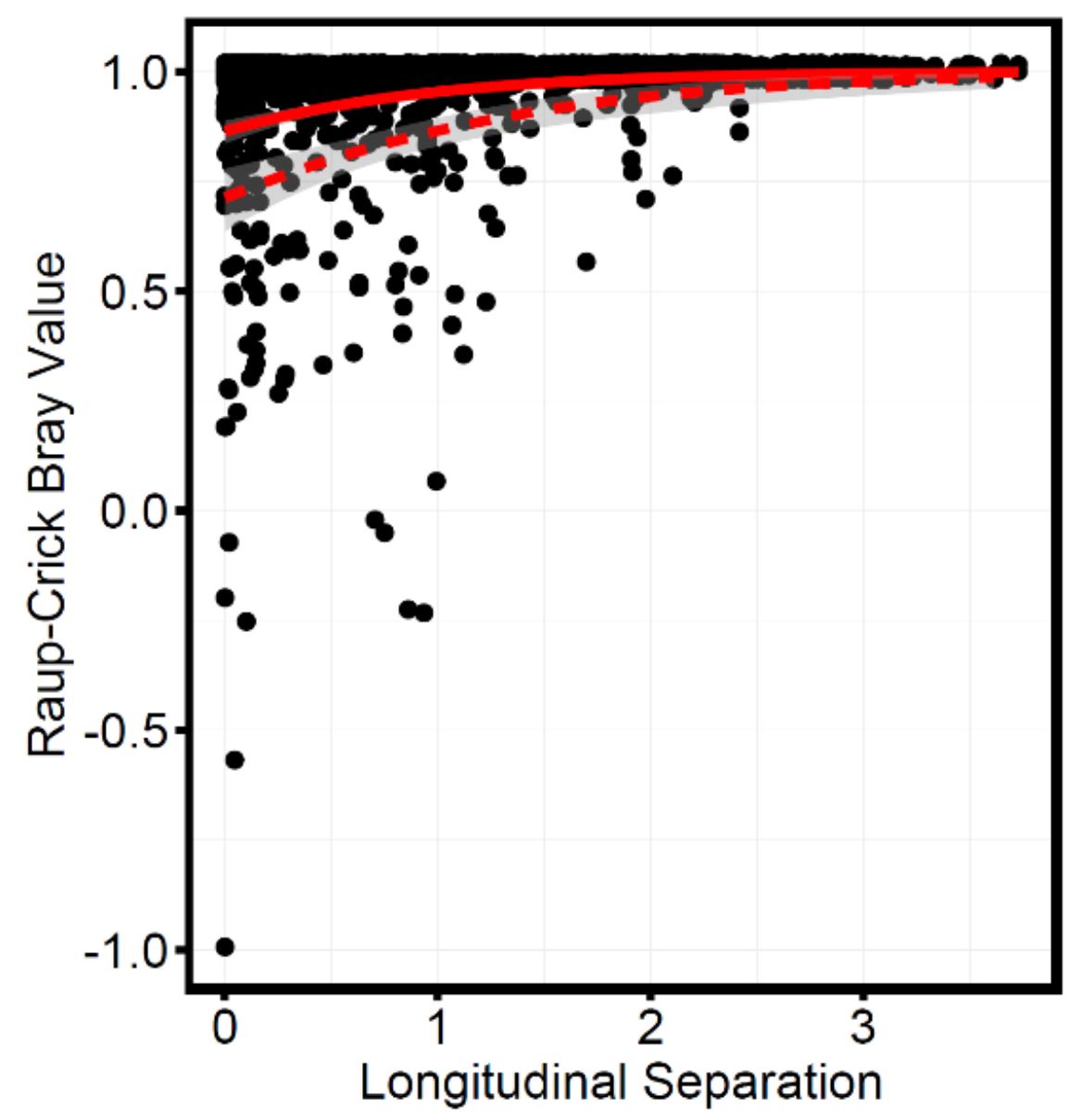

Figure 6: Scatterplot of Raup-Crick bray values versus (A) longitudinal separation of horses with best fit binomial regression grouped by whether the corresponding $\beta$ mean nearest taxon distance did (dashed: ) or did not (solid: — ) deviate from null phylogenetic expectations and (B) average longitude with best fit binomial regression coloured by whether comparisons were made between members of the same (dark purple: — ) or different (light purple: — ) social bands. Shading represent 95\% confidence intervals. 

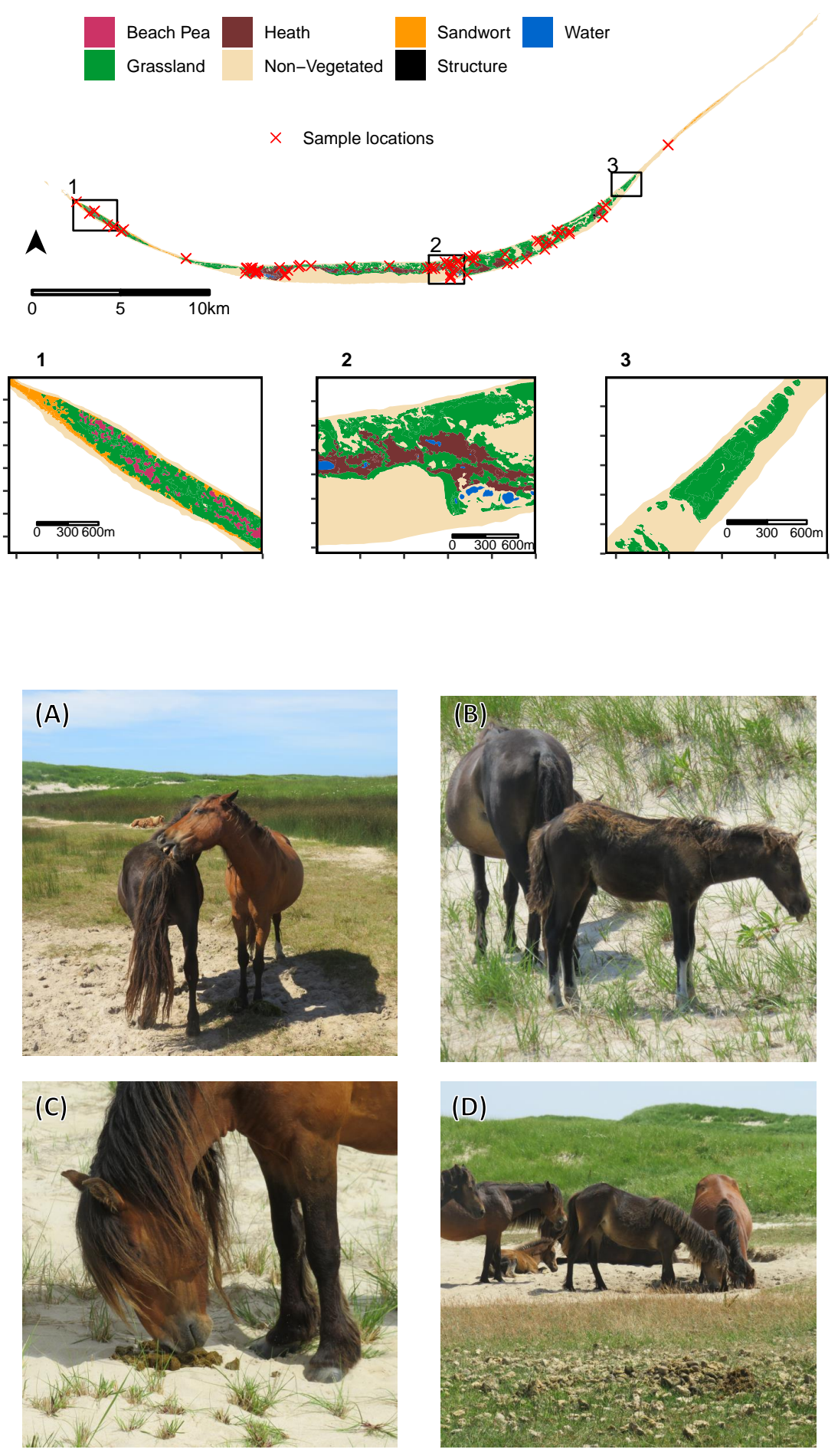


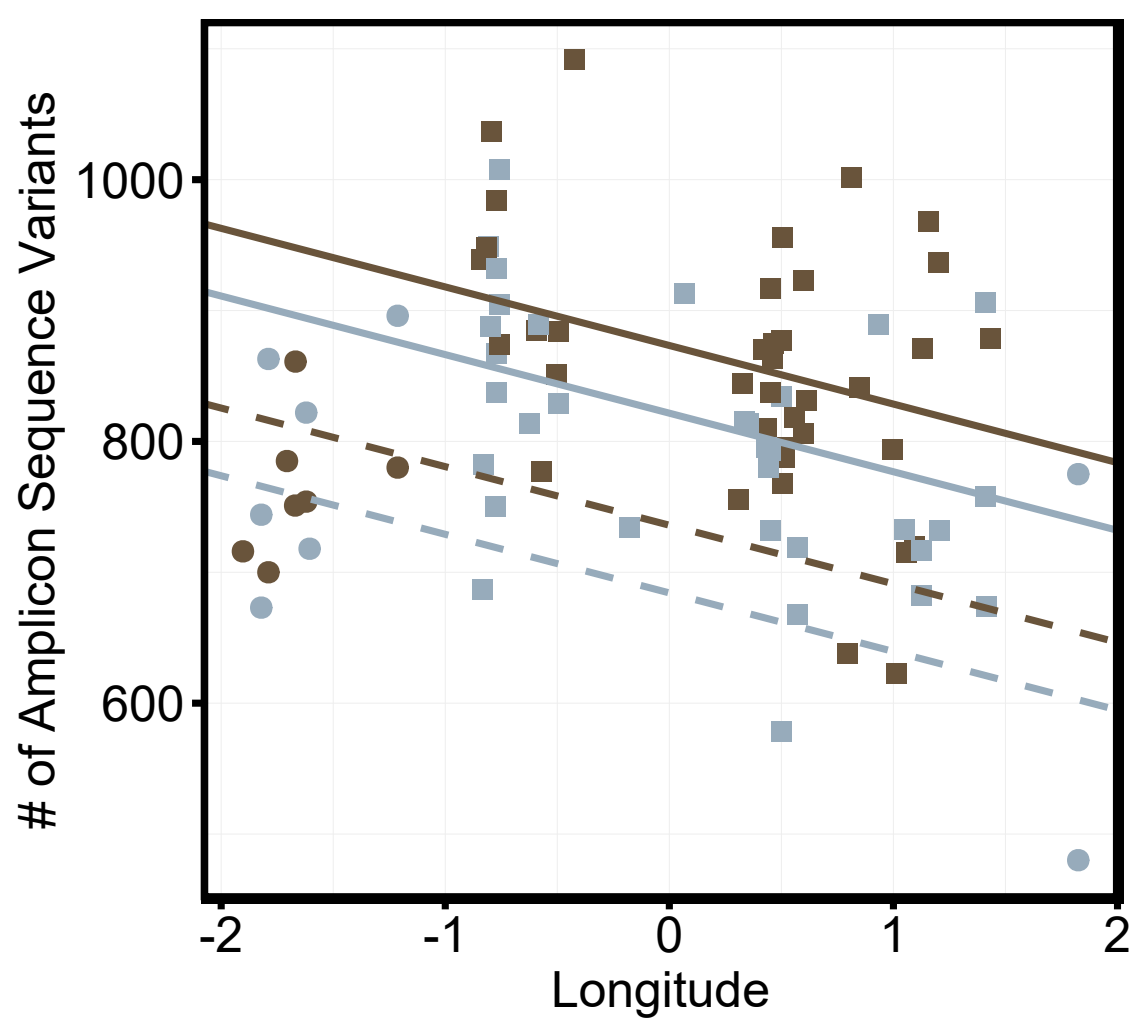

(A)

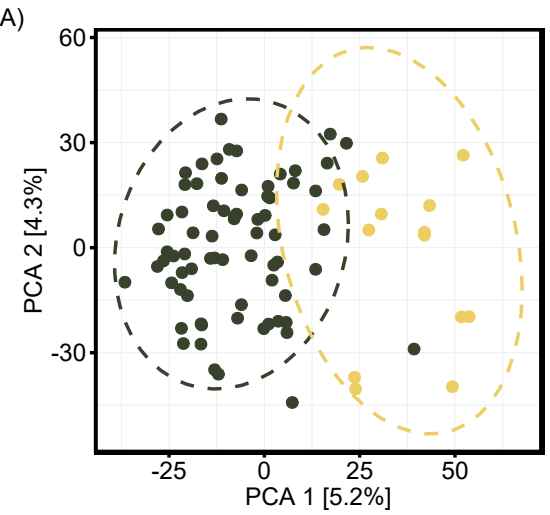

(B)

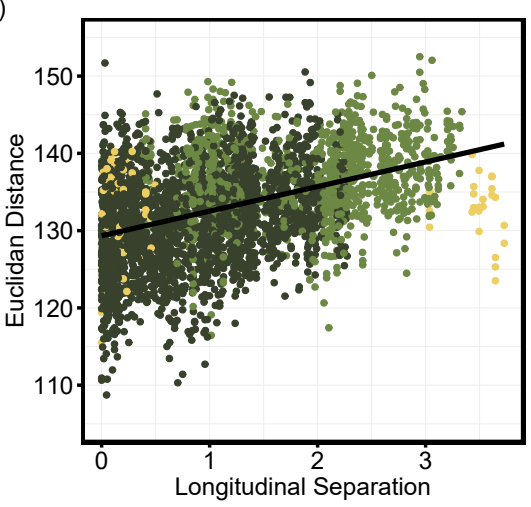

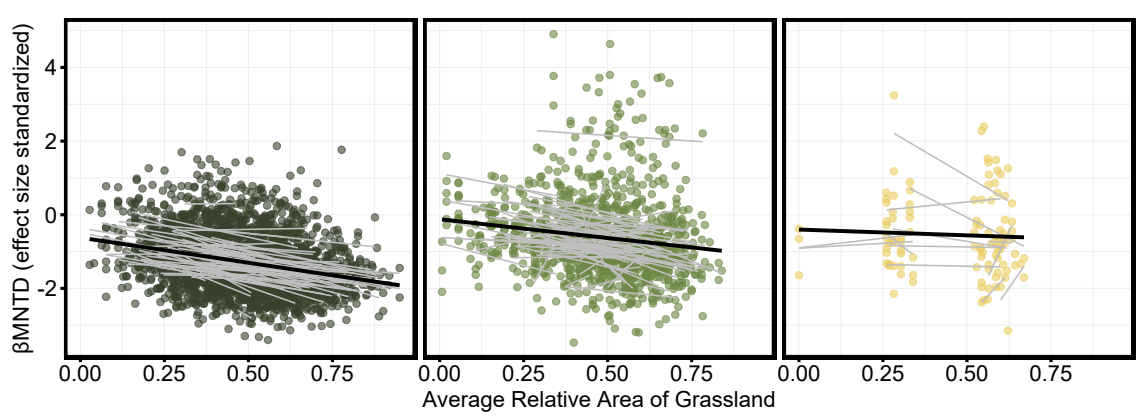


(A)

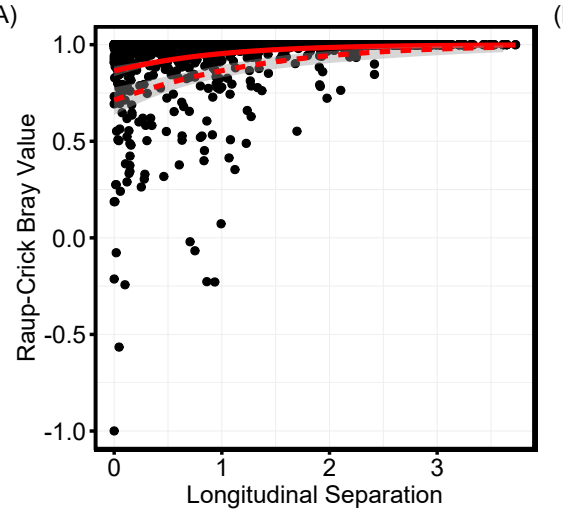

(B)

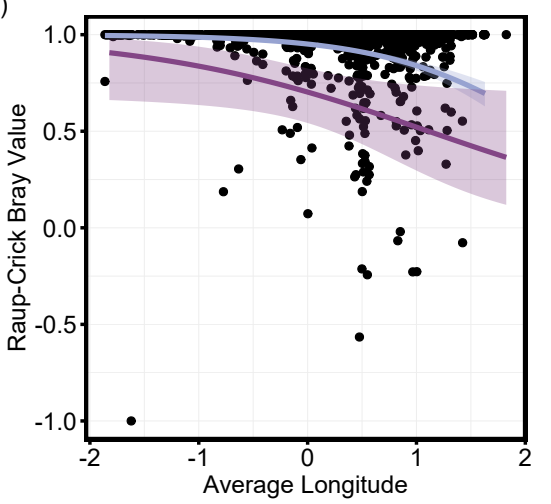

